\title{
The Critical Period for Ocular Dominance Plasticity in the Ferret's Visual Cortex
}

\author{
Naoum P. Issa, Joshua T. Trachtenberg, Barbara Chapman, Kathleen R. Zahs, and Michael P. Stryker \\ Keck Center for Integrative Neuroscience, Department of Physiology, University of California, San Francisco, \\ California 94143-0444
}

Microelectrode recordings and optical imaging of intrinsic signals were used to define the critical period for susceptibility to monocular deprivation (MD) in the primary visual cortex of the ferret. Ferrets were monocularly deprived for 2, 7 or $>14 \mathrm{~d}$, beginning between postnatal day 19 (P19) and P110. The responses of visual cortical neurons to stimulation of the two eyes were used to gauge the onset, peak, and decline of the critical period. MDs ending before P32 produced little or no loss of response to the deprived eye. MDs of $7 \mathrm{~d}$ or more beginning around P42 produced the greatest effects. A rapid decline in cortical susceptibility to MD was observed after the seventh week of life, such that MDs beginning between P50 and P65 were approximately half as effective as those beginning on P42; MDs beginning after P100 did not reduce the response to the deprived eye below that to the nondeprived eye. At all ages, $2 \mathrm{~d}$ deprivations were $55-85 \%$ as effective as $7 \mathrm{~d}$ of MD. Maps of intrinsic optical responses from the deprived eye were weaker and less well tuned for orientation than those from the nondeprived eye, with the weakest maps seen in the hemisphere ipsilateral to the deprived eye. Analysis of the effects of $7 \mathrm{~d}$ and longer deprivations revealed a second period of plasticity in cortical responses in which MD induced an effect like that of strabismus. After P70, MD caused a marked loss of binocular responses with little or no overall loss of response to the deprived eye. The critical period measured here is compared to other features of development in ferret and cat.

Key words: monocular deprivation; area 17; orientation; pinwheel; cortical columns; intrinsic signal imaging; strabismus
The pathways that convey visual input to the primary visual cortex are precisely organized in normal adult mammals and have been extensively investigated in cats, monkeys, and ferrets. In the cat, precision in retinal and subcortical organization is attained before the end of the first week of postnatal life (Shatz, 1983), at which time much of the specificity of cortical cell responses has yet to emerge. The development of precision in visual cortical responses and connections takes place in the context of functional inputs, allowing activity-dependent mechanisms to participate in this process. The influence of neural activity in the development of the visual cortex is most powerfully evident in the phenomenon of the "critical period", in which an alteration in the normal pattern of activity during a period in early life dramatically alters cortical inputs and responses, whereas a similar alteration later in life has no detectable effect (Wiesel and Hubel, 1963).

The critical period for ocular dominance plasticity has been defined as the period of susceptibility to the effects of unilateral eye closure. Temporary monocular deprivation (MD) by unilateral eye closure during the critical period decreases the respon-

\footnotetext{
Received April 6, 1999; revised May 20, 1999; accepted May 21, 1999.

This work was supported by National Institutes of Health Grant EY02874 (M.P.S.) and National Research Service Award postdoctoral fellowships (N.P.I. and J.T.T.). Michael Crair provided software for both stimulus generation and image analysis. Members of the Stryker lab provided helpful discussion and comments on this manuscript.

N.P.I. and J.T.T. contributed equally to this work.

Correspondence should be addressed to Prof. Michael P. Stryker, Department of Physiology, Room S-762, 513 Parnassus Avenue, University of California, San Francisco, CA 94143-0444.

Dr. Chapman's present address: Center for Neuroscience, University of California, Davis, CA 95616.

Dr. Zah's present address: Department of Physiology, University of Minnesota, Minneapolis, MN 55455.

Copyright (C) 1999 Society for Neuroscience $\quad 0270-6474 / 99 / 196965-14 \$ 05.00 / 0$
}

siveness of cells in primary visual cortex (V1) to the deprived eye (Wiesel and Hubel, 1963; Hubel and Wiesel, 1970). The peak of the critical period (postnatal weeks 4-6 in the cat) corresponds to the time in normal development during which geniculocortical axons attain their mature organization in the form of ocular dominance columns (LeVay et al., 1978; Antonini and Stryker, 1993a,b). In addition, events that occur during the critical period are essential for the normal maturation of neuronal response properties: in cats continuously deprived of patterned visual experience from birth, organized orientation-selective responses develop normally until the beginning of the critical period at postnatal week 4, but are then lost over the next 3 weeks (Crair et al., 1998). All of these findings are consistent with the notion that the maturation of cortical response properties relies in part on activity-dependent mechanisms that are driven by the patterns of neural activity present during normal development.

The ferret, because of the relative immaturity of its visual system at birth (Jackson and Hickey, 1985), its large litter size, and its complex visual system, has become a model preparation for studies of early visual development. In primary visual cortex, studies have described the development of orientation preference at the single unit level (Chapman and Stryker, 1993), the establishment of orientation maps (Chapman et al., 1996a; Weliky and Katz, 1997), the development and refinement of horizontal connections in the supragranular layers (Dalva and Katz, 1994; Weliky and Katz, 1994; Nelson and Katz, 1995; Durack and Katz, 1996; Ruthazer and Stryker, 1996), and the formation of interlaminar connections (McAllister et al., 1995, 1996, 1997; Callaway and Lieber, 1996; Dantzker and Callaway, 1998). These studies, together with those characterizing the organization of mature ferret V1 (Law et al., 1988; Zahs and Stryker, 1988; Chapman et al., 1991; Hirsch, 1995; Weliky et al., 1996; Rao et al., 
1997), provide one of the most complete descriptions of the role of intrinsic and extrinsic factors in patterning the visual system.

The experiments presented here investigate the effects of monocular deprivation on the organization of the ferret primary visual cortex. First, the temporal extent of the critical period for ocular dominance column plasticity is determined. The critical period in ferret visual cortex begins well after the time at which visual responses may be elicited, and, as in other species, spans only a few weeks in neonatal life. Next, we describe a novel type of cortical plasticity in the adult ferret. Unlike monocular deprivation during the critical period, deprivations in the adult ferret produce a strabismus-like segregation of eye-specific responses without producing an overall shift in ocular dominance. Finally, the effects of monocular deprivation on the relationship between orientation columns and ocular dominance columns are studied. In the normal cat, peaks of ocular dominance columns are closely associated with centers of orientation pinwheels (Crair et al., 1997a; Hubener et al., 1997). As a result of monocular deprivation in the cat, strong responses to the deprived eye lose orientation selectivity and are confined to patches at the peaks of deprived-eye columns, which are even more closely associated with pinwheel centers (Crair et al., 1997b). This relationship between ocular dominance peaks and pinwheel centers has been put forward as an organizing principal for the development of V1. In the ferret, MD produces a similar concentration of strong deprived-eye responses in patches in which neurons lack orientation selectivity, but there is no clear association between pinwheel centers and ocular dominance columns, suggesting that such a developmental rule is not common to all species.

Some of this work has been presented in preliminary form (Chapman et al., 1996b; Trachtenberg et al., 1998).

\section{MATERIALS AND METHODS}

Fifty-three black point sable ferrets were used for these experiments $(9$ normals, 44 monocularly deprived). All procedures were approved by the University of California at San Francisco Committee on Animal Research.

Monocular deprivation. Ferrets were anesthetized with $2 \%$ halothane in a 2:1 mixture of nitrous oxide-oxygen or $2.5 \%$ isoflurane in oxygen administered by face mask. After disinfecting skin around the eye to be deprived, eyelid margins were trimmed, chloramphenicol ophthalmic ointment (Parke-Davis, Morris Plains, NJ) was instilled in the eye, and the eyelids were sutured shut using two or three horizontal mattress stitches.

Surgical preparation. In preparation for electrophysiological recording or imaging, ferrets were anesthetized, and the primary visual cortex was exposed. Anesthesia was induced using a volatile agent $(2 \%$ halothane in 2:1 nitrous oxide-oxygen or $2.5 \%$ isoflurane in oxygen). An intravenous catheter was inserted. Animals were placed on a regulated heating pad and maintained at core temperature of $37.7^{\circ} \mathrm{C}$. Atropine $(0.1 \mathrm{mg})$ and dexamethasone $(0.4 \mathrm{mg})$ were administered subcutaneously to minimize tracheal secretions and stress responses. A tracheotomy was performed. Thereafter, animals were either maintained on $1-2 \%$ isoflurane in oxygen or infused intravenously with sodium thiopental and ventilated with 2:1 nitrous oxide-oxygen after discontinuing the inhaled anesthetic. Animals were then paralyzed with gallamine triethiodide (10 $\left.\mathrm{mg} \cdot \mathrm{kg}^{-1} \cdot \mathrm{hr}^{-1}\right)$ or pancuronium bromide $(1 \mathrm{mg} / \mathrm{kg})$ in $2.5 \%$ dextrose lactated Ringer's solution administered intravenously. Peak expiratory $\mathrm{CO}_{2}$, expiratory pressure, rectal temperature, electrocardiogram, and, when ferrets were old enough to allow useful interpretation, electroencephalogram were monitored. Respiratory rate and volume were adjusted to keep the peak $\mathrm{CO}_{2}$ between 3.5 and $4.5 \%$. Level of anesthesia was determined by monitoring the ratio of low and high frequency activity in the EEG or by monitoring the heart rate and peak $\mathrm{CO}_{2}$.

Once the level of anesthesia had reached surgical plane, animals were placed in a stereotaxic apparatus. Atropine sulfate (1\% solution) and phenylephrine hydrocholoride drops ( $10 \%$ solution) were instilled into the eyes, and the eyes were fitted with contact lenses to prevent desicca- tion. Visual cortex was exposed through a craniotomy, and the dura mater was reflected using a dura hook. The exposed cortex was covered with a layer of low-melting point agarose (3\% in standard saline).

Electrophysiology. Extracellular recordings of single and multiple units were made using resin-coated tungsten electrodes with tip resistances between 1 and $5 \mathrm{M} \Omega$. Areas 17 and 18 meet near the midline of the lateral gyrus, area 17 running along the caudal surface of the gyrus, and area 18 along the rostral surface. To ensure that recordings were made from area 17, electrode penetrations were made in the caudal portion of the gyrus. For the majority of penetrations, differences in receptive field properties between areas 17 and 18, including size of receptive field and progression of visual fields, were used to verify that penetrations were in area 17. Oriented stimuli were generated with a hand lamp and presented first binocularly, then to each eye individually. Ocular dominance was classified based on the seven-point scale of Hubel and Wiesel (1962), in which a unit with ocular dominance rating of 1 is entirely dominated by the contralateral eye, 4 is driven equally by the eyes, and 7 is entirely dominated by the ipsilateral eye.

Whereas ocular dominance ranking classifies the ratio of contralateral to ipsilateral eye input to a single unit, the contralateral bias index (CBI) measures the degree to which the entire population of units is dominated by the contralateral eye. CBI is calculated as in Reiter et al. (1986; but presented here as a ratio, not a percentage):

$$
\mathrm{CBI}=\frac{\left(N_{1}-N_{7}\right)+\frac{2}{3} \cdot\left(N_{2}-N_{6}\right)+\frac{1}{3} \cdot\left(N_{3}-N_{5}\right)+N_{\mathrm{T}}}{2 \cdot N_{\mathrm{T}}} ;
$$

in which $N_{\mathrm{T}}$ is the total number of visually responsive units and $N_{\mathrm{x}}$ is the number of units with ocular dominance rating $x$. A CBI of 0 indicates that the ipsilateral eye dominates the population of measured units, whereas a CBI of 1 indicates that the contralateral eye dominates the population. This index is designed so that a one-category error in the assessment of ocular dominance would cause the same change in the value of the CBI no matter in which ocular dominance category it occurs.

Because monocular deprivation produces reciprocal shifts in CBI for the hemisphere ipsilateral and contralateral to the deprived eye, we used the difference in CBIs as a measure of the degree of shift. The shift index is defined as:

$$
\mathrm{SI}=\mathrm{CBI}_{\mathrm{ipsi}}-\mathrm{CBI}_{\text {contra }} \text {; }
$$

in which $C B I_{\mathrm{ipsi}}$ is the $\mathrm{CBI}$ of the hemisphere ipsilateral to the deprived eye and $C B I_{\text {contra }}$ is the CBI of the hemisphere contralateral to the deprived eye. A shift index of +1 suggests that both hemispheres are entirely dominated by the nondeprived eye, whereas a shift index of -1 would mean that both hemispheres were entirely dominated by the deprived eye. This index has the advantage that a normal brain would be expected to have a shift index of 0 , regardless of the normal CBI of the animal.

The CBI and shift index used here and in our earlier reports are similar in spirit to those used by other authors. For example, our CBI is equal to $1-$, the "weighted ocular dominance" index of Daw et al. (1992), and our shift index is equal to the sum of the shift indices calculated separately for the two hemispheres by these authors.

The monocularity index (MI) reflects the degree to which cortical responses are dominated by one eye or the other but not by both (Stryker and Harris, 1986). The MI is defined as:

$$
\mathrm{MI}=\frac{\left(N_{1}+N_{7}\right)+\frac{2}{3}\left(N_{2}+N_{6}\right)+\frac{1}{3}\left(N_{3}+N_{5}\right)}{N_{\mathrm{T}}} .
$$

An MI of 0 suggests that all individual cells are driven equally by both eyes, whereas an MI of 1 suggests that all cells are driven exclusively by one eye or the other.

Throughout the text, all indices are expressed as a mean value \pm the SE. Unless otherwise noted, the Mann-Whitney $U$ test was used to test for statistical significance.

Histology. To determine the laminar position of recorded units, electrolytic lesions were made at defined locations along the electrode penetration. At the end of the recording session, a lethal bolus of thiopental was administered, and animals were perfused transcardially first with phosphate buffer, then with $4 \%$ paraformaldehyde. Brains were post-fixed in $4 \%$ paraformaldehyde for several days, then blocked and cut 
on a vibratome into coronal sections 50 - to 70 - $\mu$ m-thick. Sections were mounted on glass slides and stained with cresyl violet. Laminar assignments were made from camera lucida drawings of the cortical laminae and lesions.

Imaging intrinsic signals. We imaged intrinsic signals from V1 and V2 in response to visual stimuli using the ORA 2001 Optical Recording Acquisition and Analysis System (Optical Imaging, Germantown, NY). Before imaging, a new layer of agarose and a cleaned coverslip were placed over visual cortex. The cortical surface was illuminated using a tungsten-halogen light source. Illumination wavelength was set using either a green $(546 \pm 10 \mathrm{~nm})$ or red $(610 \pm 10 \mathrm{~nm})$ interference filter. Initially, a green image of the surface vascular pattern was taken. The camera was then focused $400 \mu \mathrm{m}$ below the pial surface, at approximately the depth of layer III. Images of intrinsic signals were acquired using the red filter for illumination, and an identical red filter was positioned between the brain and CCD camera. Full-field grating stimuli were produced by a VSG 2/3 board (Cambridge Research Systems, Rochester, UK) controlled by custom software. Gratings had a spatial frequency of 0.15 cycles $/{ }^{\circ}$ and moved with a temporal frequency of 2 cycles/sec. Four to six cycles were visible on a 21 inch monitor (Nokia $445 \mathrm{X}$ ) placed $40 \mathrm{~cm}$ from the animal. Stimuli moved in a direction perpendicular to the long axis of the grating, and reversed direction of motion every $2 \mathrm{sec}$. Stimulus orientation was selected pseudorandomly from four or eight evenly spaced templates spanning $180^{\circ}$; reversal of direction of motion gave the full $360^{\circ}$ range of orientations. Four blank-screen stimuli (both eye shutters closed) were interleaved with the monocularly presented oriented stimuli; the average of the images collected during these blankscreen stimuli is the blank image. During a single stimulus presentation, 20 frames of $300 \mathrm{msec}$ duration [CCD binning set to $2 ; 1$ pixel $=(16.7$ $\mu \mathrm{m})^{2}$ ] or 10 frames of $600 \mathrm{msec}$ duration [CCD binning set to $1 ; 1$ pixel = $(22.5 \mu \mathrm{m})^{2}$ ] were acquired. The twelve or twenty conditions (4 orientations $\times 2$ eyes +4 blanks $=12$ conditions, or 8 orientations $\times 2$ eyes + 4 blanks $=20$ conditions) were repeated 16 times to constitute a single run. Two to five runs were analyzed for each experiment. The illumination shutter, a Uniblitz VS35 shutter (Vincent Associates, Rochester, NY), and custom-built eye shutters were controlled by the stimulus and acquisition computers.

Images were analyzed using commercial (ORA 2000) and custom software written in the Interactive Data Language (Research Systems, Boulder, CO). Because the dominant component of the stimulus-induced intrinsic signal develops over $1-2 \mathrm{sec}$, the first $1.2 \mathrm{sec}$ acquired under each condition were disregarded. The signal-to-noise ratio in images was improved by averaging the same condition over all remaining frames, repetitions, and runs. Images were then normalized either to the average of the four blank images (blank normalized) or to the average of all conditions except the blanks (cocktail-blank normalized). Ferret V1 is highly vascularized; areas of the image with vascular artifacts were removed by overlaying functional images with a template of the vascular pattern derived by digitally thresholding the average blank image (in which the surface vasculature is present but out of focus). Ocular dominance ratio maps showed the ratio between the average responses over all conditions for the two eyes. Angle and hue lightness saturation (HLS) maps were constructed as outlined in Bonhoeffer and Grinvald (1996). Hues in the angle map represent the stimulus orientation to which the pixel responds most strongly. In the HLS maps, all of which were constructed from blank-normalized images, hue represents the best stimulus orientation, lightness represents the activity of the pixel (regardless of orientation-selectivity), and saturation represents the degree of orientation selectivity.

An optical CBI was calculated from blank normalized images using a protocol slightly different from that of Crair et al. (1998). The ocular dominance rating of each pixel (OD) was calculated as follows:

$$
\mathrm{OD}=\frac{\text { Pixel }_{\mathrm{Max}}-\text { Pixel }_{\mathrm{Eye} 2}}{\text { Pixel }_{\mathrm{Max}}-1}
$$

in which Pixel ${ }_{\mathrm{Max}}$ is the strongest response at a given pixel, and Pixel $_{\mathrm{Eye} 2}$ is the pixel intensity for the same stimulus orientation as for Pixel $_{\mathrm{Max}}$, but for the other eye. Because the images are blank-normalized, image intensities fluctuate around 1.0; the denominator therefore represent the difference between the response at the best orientation and the response to a blank screen. In some pixels in each image, the best response was smaller than or equal to the response to a blank screen; these pixels (always $<10 \%$ of the total) were not included in the calculation of the CBI. The distribution of OD ratings for all pixels in the image was binned, and a weighted average was calculated to produce the Optical CBI ranging between 0 (for complete dominance of the ipsilateral eye) and 1 (representing complete dominance of the contralateral eye).

For Monte Carlo simulations of the distance between ocular dominance column peaks and pinwheel centers (Crair et al., 1997a,b), ocular dominance peaks were selected from cocktail-blank normalized ocular dominance ratio maps by calculating the centroid position of regions within a digitally thresholded image. Threshold values were adjusted manually to identify regions around ocular dominance column peaks. Pinwheel centers were selected either using a curl function algorithm or manually from angle maps. The distance between each ocular dominance peak and its nearest pinwheel center was calculated. Individual Monte Carlo simulations were produced by randomly placing pinwheel centers on the image while keeping ocular dominance peaks fixed; 5000 simulations were made for each map. Combining the simulations from all hemispheres produced the cumulative Monte Carlo distribution.

\section{RESULTS}

\section{Electrophysiological characterization of the ferret's ocular dominance critical period}

To define the critical period for ocular dominance plasticity in the ferret's primary visual cortex, we assessed ocular dominance from extracellular responses in both normal and monocularly deprived ferrets. Ferrets ranging in age from postnatal day 19 (P19) through adult were monocularly deprived by lid suture for periods of 2, 7, or $>14 \mathrm{~d}$. A total of 2772 units were recorded in 51 animals: 1294 from the hemisphere ipsilateral to the deprived eye (or the right eye in normal animals) and 1478 from the contralateral (or left) hemisphere. Cells were classified based on their responses to each eye using the seven-point ocular dominance scale developed by Hubel and Wiesel (1962). For each cortical hemisphere, we calculated the contralateral bias index (CBI), a measure of the dominance of input from the contralateral eye, and the monocularity index (MI), a measure of how skewed the distribution of ocular dominance is toward the extremes of the classification scale (1 and 7). The magnitude of the cortical shift after monocular deprivation was determined using the shift index (SI), defined as the difference in CBIs between the hemispheres ipsilateral and contralateral to the deprived eye (see Materials and Methods).

To ensure that the neurons sampled during electrophysiological recordings were in area 17 , electrode penetrations were made in the caudal portion of the lateral gyrus, avoiding the more rostral area 18. The medial aspect of the dorsal portion of the lateral gyrus in most ferrets has a different arrangement of ocular dominance columns from the rest of area 17 (Rockland, 1985; Law et al., 1988; Redies et al., 1990; Ruthazer et al., 1999). In this area, ocular dominance columns can extend for several millimeters parallel to the border between areas 17 and 18 (Fig. $4 E$ and below). Nearly all of the ocular dominance data were collected from tangential penetrations extending several millimeters through the more lateral and caudal region of the dorsal surface of area 17, which typically has the normal periodic arrangement of ocular dominance columns. The idiosyncratic nature of the unusual ocular dominance columns, however, makes it impossible to be certain in every case that the electrode was recording from the region of conventional ocular dominance columns (with a period of $\sim 1 \mathrm{~mm}$ ).

Ocular dominance in normal animals was studied to establish baseline values of contralateral bias and monocularity. We studied seven animals ranging in age from P39 to adult (Fig. 1). As has been noted in young kittens (Crair et al., 1998), young ferrets have a strong contralateral bias (mean CBI $=0.75 \pm 0.04 ; n=3$ hemispheres from two animals younger than P66). By P84 the $\mathrm{CBI}$ has decreased to adult levels (for nine normal hemispheres in 


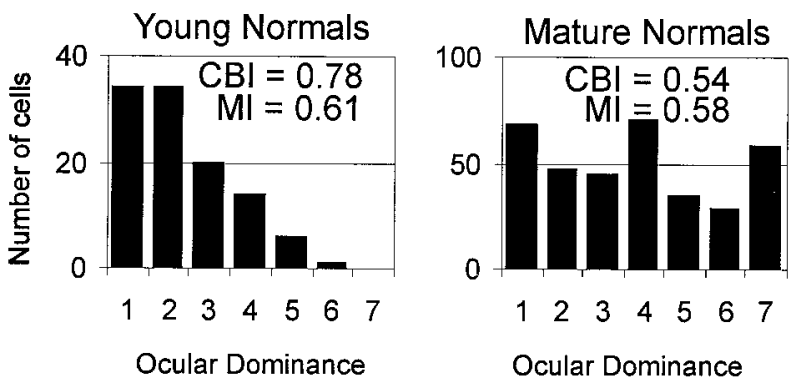

Figure 1. Normal ocular dominance histograms. The number of recorded units with a given ocular dominance rating (1, dominated by contralateral eye; 7 , dominated by ipsilateral eye) are plotted for young normal (P65 or younger) and mature normal ferrets (P80 or older). In both age groups, a large fraction of the recorded units are driven by both eyes. Young ferrets have a stronger bias toward the contralateral eye than do mature ferrets. The CBI and MI shown with each histogram are calculated from the distribution of units plotted. The values derived from these pooled histograms differ slightly from the CBIs and MIs given in Results; the indices in the text are averages of the CBI or MI from individual hemispheres.

five animals P84 and older, mean CBI $=0.50 \pm 0.05$ ). The adult $\mathrm{CBI}$ reported here is smaller than has been previously documented (adult $\mathrm{CBI}=0.59$ for the central $10^{\circ}$ degrees of the visual field; Law et al., 1988). Although young ferrets have a larger contralateral bias than adult ferrets, they are, on average, similarly binocular. The two normal ferrets younger than P66 had an average MI of $0.56 \pm 0.04(n=3$ hemispheres $)$, whereas the average MI for the five animals P84 or older was $0.63 \pm 0.06(n=$ 9 hemispheres).

To determine whether monocular deprivation during early life would have an effect on cortical responsiveness to the two eyes, nine animals were monocularly deprived for periods of 2 weeks or longer. Cortical responses in animals whose deprivation began at P30 were consistently shifted in favor of the nondeprived eye $(n=$ 4 ; $\mathrm{SI}=0.75 \pm 0.10$; Fig. $2 B$, dashed line; Table 1$)$. In general, the hemisphere ipsilateral to the deprivation became almost entirely dominated by the nondeprived eye (CBI ipsilateral $=0.99 \pm 0.01$; Table 1), whereas the contralateral hemisphere retained a small amount of input from the deprived eye (CBI contralateral = $0.24 \pm 0.09)$. Later deprivation was less effective in shifting cortical responses toward the open eye. Monocular deprivations begun on P114-116 $(n=2)$ or as adults $(n=2)$ appeared ineffective, yielding shift indices $(\mathrm{SI}=0.01 \pm 0.05)$ similar to those expected for normal ferrets.

We used brief monocular deprivations to probe more precisely the extent of the critical period for ocular dominance. Twentythree ferrets experienced 7 or $8 \mathrm{~d}$ of monocular vision beginning at ages ranging from P19 to P110. Monocular deprivations had a profound effect on cortical response properties when begun within the first $10 \mathrm{~d}$ after the time of natural eye opening (P32). Ocular dominance histograms from the two hemispheres of three ferrets deprived at P35 are shown in Figure $2 A$. A week of deprivation at P35 ( $\mathrm{SI}=0.83 \pm 0.12)$ was as effective at shifting ocular dominance as deprivations of 2 weeks or longer that started at P30. In animals deprived starting around P42, the shift in ocular dominance was the largest observed of all age groups and durations, and represents a nearly complete shift to the nondeprived eye $(\mathrm{SI}=0.90 \pm 0.04)$.

The time course of the effect of 1 week of monocular deprivation on the ocular dominance response of cortical neurons is apparent in the shift indices and CBIs plotted in Figure 2, $B$ and
C. A week of deprivation produced little or no discernable shift when begun on or before P21 (SI $=0.05 \pm 0.04 ; n=5)$. After $\mathrm{P} 42$, monocular deprivations grew progressively less effective in altering cortical response properties. Monocular deprivations beginning around P60 were approximately half as effective as deprivations at the peak of the critical period, and monocular deprivations beginning after P100 failed to shift ocular dominance toward the open eye.

In cats, monocular deprivation for $2 \mathrm{~d}$ at the peak of the critical period results in a saturating shift in cortical response properties to favor the open eye (Hubel and Wiesel, 1970; Olson and Freeman, 1975; Crair et al., 1997b). To determine whether very brief deprivations are also saturating in the ferret, we examined the effects of $2 \mathrm{~d}$ of monocular deprivation on ocular dominance in 12 ferrets. The effects of $2 \mathrm{~d}$ MDs paralleled the time course of the critical period described above, but were appreciably less pronounced than the effects of $7 \mathrm{~d}$ of deprivation. At the peak of the critical period, between P35 and P60, 2 d deprivations produced a shift index that was $55-85 \%$ as large as that after $7 \mathrm{~d}$ of monocular deprivation (Fig. 2B). Ferrets, unlike cats, therefore require $>2 \mathrm{~d}$ of monocular vision, even at the peak of the critical period, to produce a saturating shift in ocular dominance.

To determine whether the magnitude of ocular dominance plasticity varied among cortical layers, we reconstructed electrode penetrations from histological sections of brains from animals that had been monocularly deprived for $7 \mathrm{~d}$. Figure $2 D$ shows the shift index of each lamina versus age at deprivation. As has been reported for other species (cat, Shatz and Stryker, 1978; mouse, Gordon and Stryker, 1996; macaque, Hubel et al., 1977), the shift in ocular dominance in layer IV was of smaller magnitude than that recorded in the extragranular cortical layers. The strongest effects of monocular deprivation were seen in layer VI. The critical period begins at the same time in all layers, and ends somewhat earlier in layer IV than in the other layers.

\section{MD in adult ferrets induces a strabismus-like effect in V1}

The reduction in the response to the deprived eye that follows monocular deprivation during the critical period necessarily reduced the extent to which visual cortical neurons are driven binocularly. We measured the extent of monocular, as opposed to binocular, responsiveness by calculating the monocularity index for each cortical hemisphere (see Materials and Methods). In Figure 3, the monocularity index of the cortical hemispheres is plotted as a function of the age at deprivation. Deprivations initiated before the onset of the critical period produced little reduction in response to the deprived eye and left most cells with binocular responses, resulting in low values of the monocularity index (Fig. 3B). As expected, deprivations during the peak of the critical period caused a sharp increase in monocularity compared to normals (compare Figs. $2 A, 1$ ). Deprivations near the end of the peak of the critical period $(\sim$ P58) produced a smaller increase in monocularity than did deprivations at the peak of the critical period ( $p<0.025$; comparing M Is for $7 \mathrm{~d}$ deprivations at P58 to those at P42).

Surprisingly, however, monocular deprivations beginning after the end of the critical period produced monocularity indices that were larger than both the MI found for deprivations at P58 ( $p<$ 0.05; comparing M Is for $7 \mathrm{~d}$ deprivations at P58 to those at P86) and the normal MI. Figure $3 A$ shows that monocular deprivation after the peak of the critical period left the cortex with few cells that responded well to both eyes but similar numbers of cells 
A

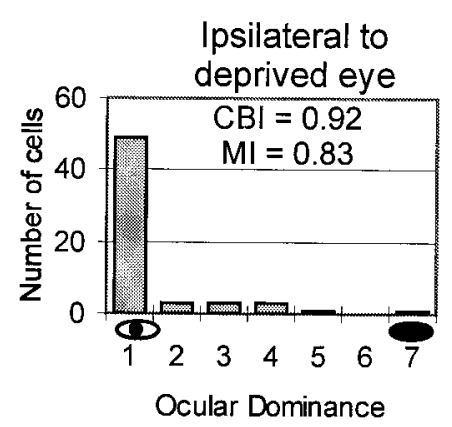

B 1

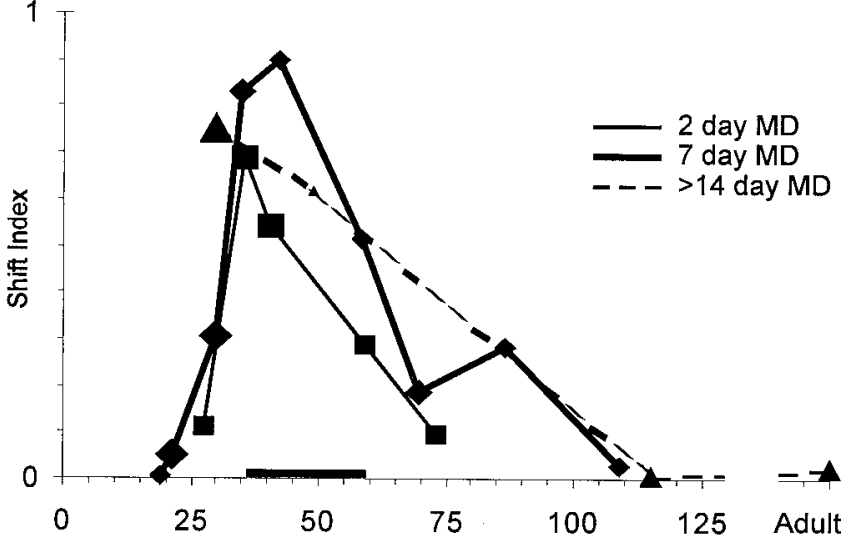

C
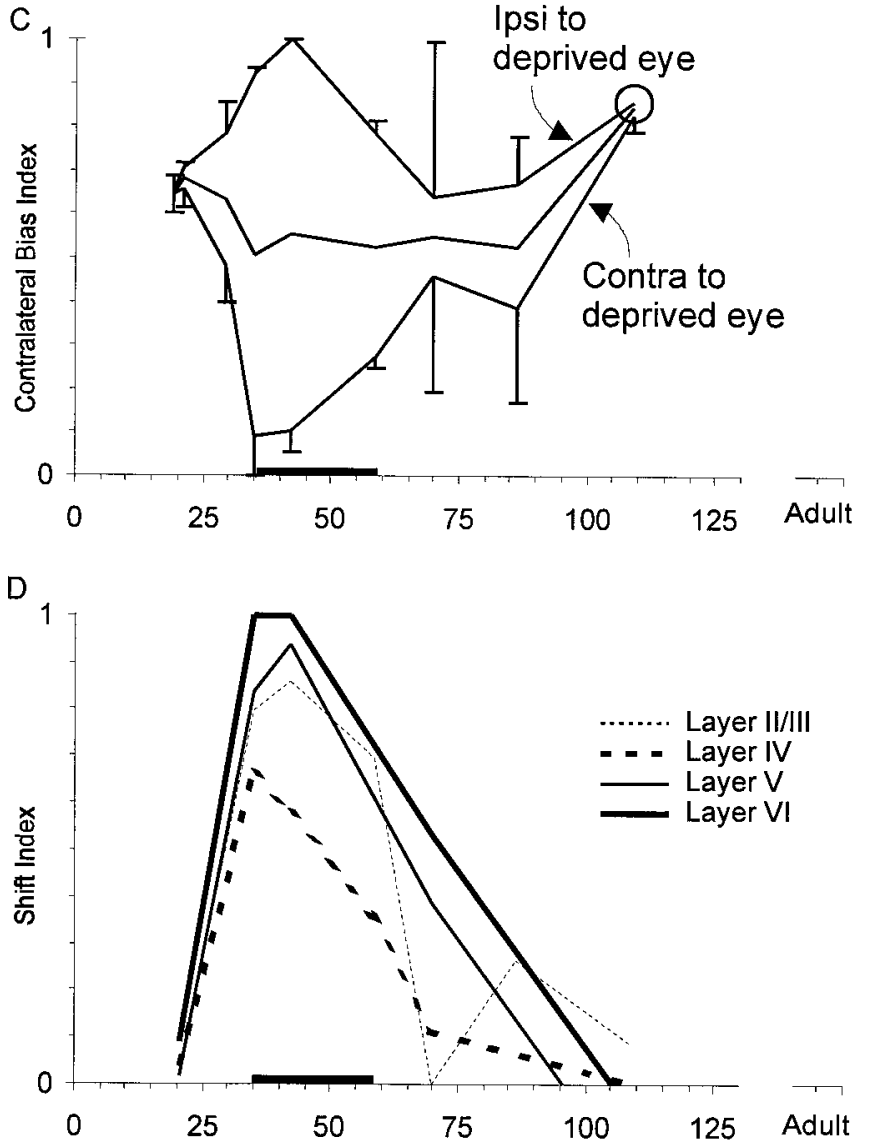

Figure 2. The effect of monocular deprivation on ocular dominance as a function of age. $A$, Ocular dominance histograms. Ocular dominance histograms are plotted for three ferrets that were monocularly deprived for 1 week starting at P35. Both the hemisphere ipsilateral to and that dominated by the deprived and nondeprived eyes. Comparison with Figure $2 A$ reveals that this effect is quite different from the loss of binocularity seen during the critical period. In eight animals, P84 or older, that were deprived for at least $7 \mathrm{~d}$, the average monocularity index of $0.86 \pm 0.02(n=15$ hemispheres $)$ was significantly different $(p<0.005)$ from that found in five normal animals $(0.63 \pm 0.06 ; n=9$ hemispheres). Such late MD produced little difference in contralateral bias between the hemispheres ipsilateral and contralateral to the deprived eye ( $\mathrm{SI}=$ $0.09 \pm 0.09 ; n=7$ deprived animals; compare to SI $=-0.08 \pm$ $0.16 ; n=4$ normal animals; Figs. 2, 3; Table 1). In these animals, both eyes are well represented in the cortex, but as in strabismic animals, few cortical cells responded well to both eyes.

The extent to which monocular deprivation altered the cortical monocularity index decreased with age, but remained strong into adulthood. From $\sim$ P70-P90, 7 d deprivations were as effective as much longer deprivations in altering monocularity (Fig. $3 B$ ). In older animals, however, deprivations of 2 weeks or longer were necessary to increase monocularity. At $\sim$ P110, 7 d deprivations produced a monocularity index of $0.74 \pm 0.03(n=3$ hemispheres in two animals), whereas $40 \mathrm{~d}$ deprivations at P115 or older gave a monocularity index of $0.87 \pm 0.02(n=8$ hemispheres in four animals; 7 and $40 \mathrm{~d}$ deprivation effects are significantly different; $p<0.025)$. The time course of susceptibility to this strabismuslike effect of MD, increasing around P70 and decreasing around $\mathrm{P} 110$, is therefore different from that of the critical period. The effect of prolonged deprivation in older animals suggests that the adult cortex remains plastic.

A laminar analysis of monocularity suggests that the strabismus-like changes that occur during adulthood are not identical to the changes that occur during the critical period. Both the $7 \mathrm{~d}$ MD series (Fig. 3C) and the $>14 \mathrm{~d}$ MD series (data not shown) have similar trends in the layers affected. During the critical period, cells in all layers became more monocular, with the most pronounced monocularity seen in layer VI. After a dip at the end of the critical period, layer IV became as monocular as layer VI, and layer V was less affected. The layer V finding is

contralateral to the deprived eye were dominated by the open (nondeprived) eye. $B$, Shift index. Shift index is plotted as a function of age at the beginning of monocular deprivation. The shift index is the difference between the CBI of the hemisphere ipsilateral to the deprived eye and the CBI contralateral to the deprived eye. The larger the shift index, the greater the effect of monocular deprivation on ocular dominance. For all three series of deprivations (bold line, $7 \mathrm{~d}$ deprivations; solid line, $2 \mathrm{~d}$ deprivations; dashed line, $>14 \mathrm{~d}$ deprivations), the shift index is greatest between P35 and P58, the peak of the critical period for ocular dominance plasticity in the ferret, indicated by the heavy line on the abscissa in parts $B-D$. The beginning of the critical period is defined by the age at which $2 \mathrm{~d}$ deprivations produce a shift index $>0.5(\mathrm{P} 35)$. The point at which the shift index for $7 \mathrm{~d}$ deprivations drops below 0.5 (P58) was taken as the end of the "peak" of the critical period. The size of a symbol is proportional to the number of animals that constitute each time point (Table 1). $C$, Contralateral bias index. The CBI for the series of $7 \mathrm{~d}$ MDs is plotted as a function of age at the beginning of monocular deprivation. Top line, CBI of the hemisphere ipsilateral to the deprived eye. Bottom line, CBI of the hemisphere contralateral to the deprived eye. Center line, Mean of the ipsilateral and contralateral CBIs. The CBI varies in a complementary fashion in the two hemispheres; both hemispheres become dominated by the nondeprived eye. Error bars indicate SEM; the circled point has only one hemisphere contributing to the CBI. D, Laminar analysis. The shift index for the series of $7 \mathrm{~d}$ MDs is plotted as a function of age at the beginning of monocular deprivation for each cortical layer. Cells in layer VI were the most affected by MD, whereas cells in layer IV were the least affected. 
Table 1. Effects of monocular deprivation of different durations as a function of age as measured by electrophysiology

\begin{tabular}{|c|c|c|c|c|c|c|c|c|c|c|c|}
\hline \multirow[b]{2}{*}{ No. Anim. } & \multirow[b]{2}{*}{ Age } & \multirow[b]{2}{*}{ MI } & \multirow[b]{2}{*}{ SEM } & \multicolumn{3}{|c|}{ Ipsilateral } & \multicolumn{3}{|c|}{ Contralateral } & \multirow[b]{2}{*}{ SI } & \multirow[b]{2}{*}{ SEM } \\
\hline & & & & NVR & $\mathrm{CBI}$ & SEM & NVR & CBI & SEM & & \\
\hline \multicolumn{12}{|l|}{ Normals } \\
\hline 1 & 39 & 0.64 & - & - & - & - & 30 & 0.82 & - & - & - \\
\hline 1 & 65 & 0.51 & 0.01 & 30 & 0.73 & - & 30 & 0.69 & - & 0.03 & - \\
\hline 1 & 84 & 0.46 & 0.04 & 30 & 0.46 & - & 30 & 0.46 & - & 0.00 & - \\
\hline 1 & 99 & 0.64 & 0.12 & 27 & 0.50 & - & 34 & 0.45 & - & 0.05 & - \\
\hline 3 & Adult & 0.69 & 0.09 & 60 & 0.41 & 0.20 & 168 & 0.62 & 0.09 & -0.21 & 0.36 \\
\hline \multicolumn{12}{|l|}{$2 \mathrm{~d} M D$} \\
\hline 2 & 28 & 0.56 & 0.07 & 50 & 0.69 & 0.06 & 30 & 0.58 & - & 0.10 & - \\
\hline 3 & 36 & 0.85 & 0.07 & 60 & 0.89 & 0.02 & 37 & 0.21 & 0.01 & 0.69 & - \\
\hline 3 & 41 & 0.74 & 0.04 & 99 & 0.83 & 0.06 & 94 & 0.29 & 0.06 & 0.54 & 0.10 \\
\hline 2 & 59 & 0.61 & 0.06 & 58 & 0.77 & 0.09 & 42 & 0.48 & 0.13 & 0.29 & 0.03 \\
\hline 2 & 73 & 0.77 & 0.04 & 62 & 0.70 & 0.16 & 67 & 0.60 & 0.20 & 0.10 & 0.29 \\
\hline \multicolumn{12}{|l|}{1 week MD } \\
\hline 2 & 19 & 0.33 & 0.02 & 57 & 0.65 & 0.04 & 60 & 0.64 & 0.04 & 0.00 & 0.08 \\
\hline 4 & 21 & 0.40 & 0.04 & 90 & 0.71 & 0.01 & 124 & 0.65 & 0.04 & 0.05 & 0.03 \\
\hline 3 & 28 & 0.63 & 0.07 & 87 & 0.79 & 0.07 & 70 & 0.48 & 0.08 & 0.30 & 0.06 \\
\hline 3 & 35 & 0.88 & 0.07 & 60 & 0.92 & 0.01 & 63 & 0.09 & 0.09 & 0.83 & 0.12 \\
\hline 2 & 42 & 0.95 & 0.03 & 56 & 1.00 & 0.00 & 66 & 0.10 & 0.05 & 0.90 & 0.04 \\
\hline 2 & 59 & 0.73 & 0.02 & 60 & 0.78 & 0.03 & 60 & 0.27 & 0.02 & 0.51 & 0.01 \\
\hline 3 & 70 & 0.86 & 0.05 & 58 & 0.64 & 0.35 & 87 & 0.46 & 0.26 & 0.19 & 0.48 \\
\hline 2 & 87 & 0.93 & 0.01 & 60 & 0.67 & 0.11 & 46 & 0.39 & 0.22 & 0.28 & 0.26 \\
\hline 2 & 109 & 0.74 & 0.03 & 39 & 0.86 & - & 64 & 0.83 & 0.04 & 0.03 & - \\
\hline \multicolumn{12}{|l|}{$>14 \mathrm{~d} \mathrm{MD}$} \\
\hline 4 & 30 & 0.85 & 0.06 & 105 & 0.99 & 0.01 & 120 & 0.24 & 0.09 & 0.75 & 0.10 \\
\hline 1 & 49 & 0.82 & 0.09 & 30 & 0.96 & - & 30 & 0.34 & - & 0.62 & - \\
\hline 2 & 115 & 0.90 & 0.02 & 58 & 0.47 & 0.03 & 60 & 0.46 & 0.07 & 0.01 & 0.10 \\
\hline 2 & Adult & 0.84 & 0.10 & 58 & 0.51 & 0.18 & 66 & 0.49 & 0.11 & 0.02 & 0.07 \\
\hline
\end{tabular}

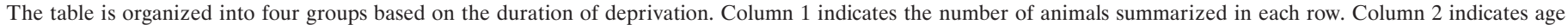

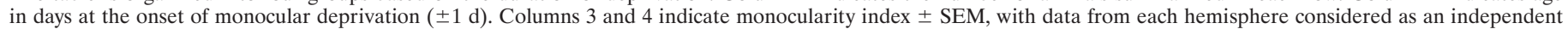

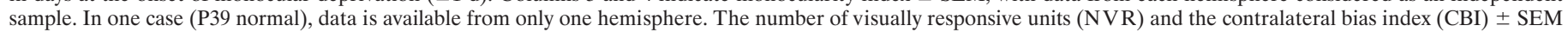

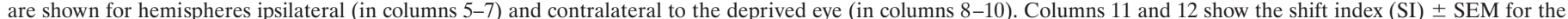

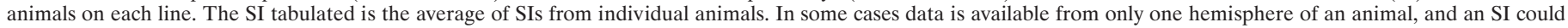

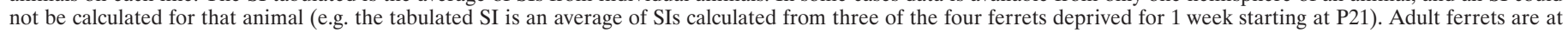
least 6 months old, but their exact ages are unknown.

somewhat paradoxical, since layer $\mathrm{V}$ cells are the most affected after very long monocular deprivations (Shatz and Stryker, 1978). It is, however, consistent with observations in the normal adult ferret, in which layer $\mathrm{V}$ cells are only $\sim 70 \%$ as monocular as layer II/III cells (data not shown). The increased monocularity of cells in layers IV and VI with monocular deprivation during adulthood suggests that cortical plasticity in adult ferrets is not limited to the supragranular layers.

\section{The relationship between the ocular dominance and orientation columnar systems in monocularly deprived ferrets}

To assess the effects of monocular deprivation on the relationship between ocular dominance and orientation columns in the ferret, we imaged cortical activity in response to oriented gratings shown to one or the other eye. Confirming earlier reports, pinwheel structures, in which orientation preference varies continuously around a central point, were evident in the normal ferrets illustrated in Figure 4 (Chapman et al., 1996a; Weliky et al., 1996; Rao et al., 1997). When images of the cortex were summed by eye rather than orientation, a map of ocular dominance was produced (Fig. $4 B, E$ ). In some, but not all, normal animals, ocular domi- nance maps showed large regions of visual cortex dominated by the ipsilateral eye; these regions were elongated mediolaterally and ran parallel to the border between areas 17 and 18 (compare the elongated white area indicating ipsilateral eye dominance in the medial half of Fig. $4 E$ with Fig. $4 B$; White et al., 1998; Ruthazer et al., 1999). Even these large areas, however, were not homogeneous, each having multiple extrema of eye dominance. In accordance with electrophysiological measures of CBI in normal animals (Fig. 1), optical imaging showed that the two eyes were similar in their efficacy at activating the cortex. A contralateral bias index calculated from the optical imaging data (optical $\mathrm{CBI}$ ), using the same principle as the electrophysiological index, had values of 0.58 and 0.54 for the hemispheres shown in Figure $4, B$ and $E$, respectively.

For animals in which monocular deprivation produced a significant shift in the electrophysiologically measured contralateral bias index, the optical responses were also abnormal. The effects of monocular deprivation on optical maps depended strongly on the age at the onset of deprivation. Figure 5 contrasts optical maps from an animal with a large shift in ocular dominance after MD $(A-E, \mathrm{~F} 309 \mathrm{C}$; $\mathrm{SI}=0.90 ; 19 \mathrm{~d}$ MD beginning at P30) with 
A

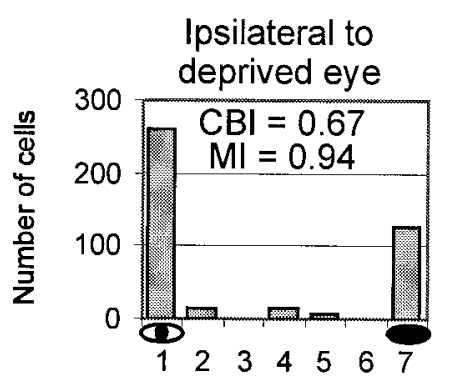

\section{Adult MD}

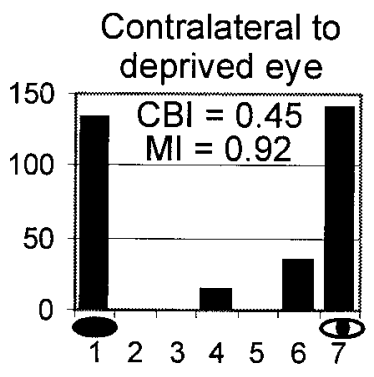

B
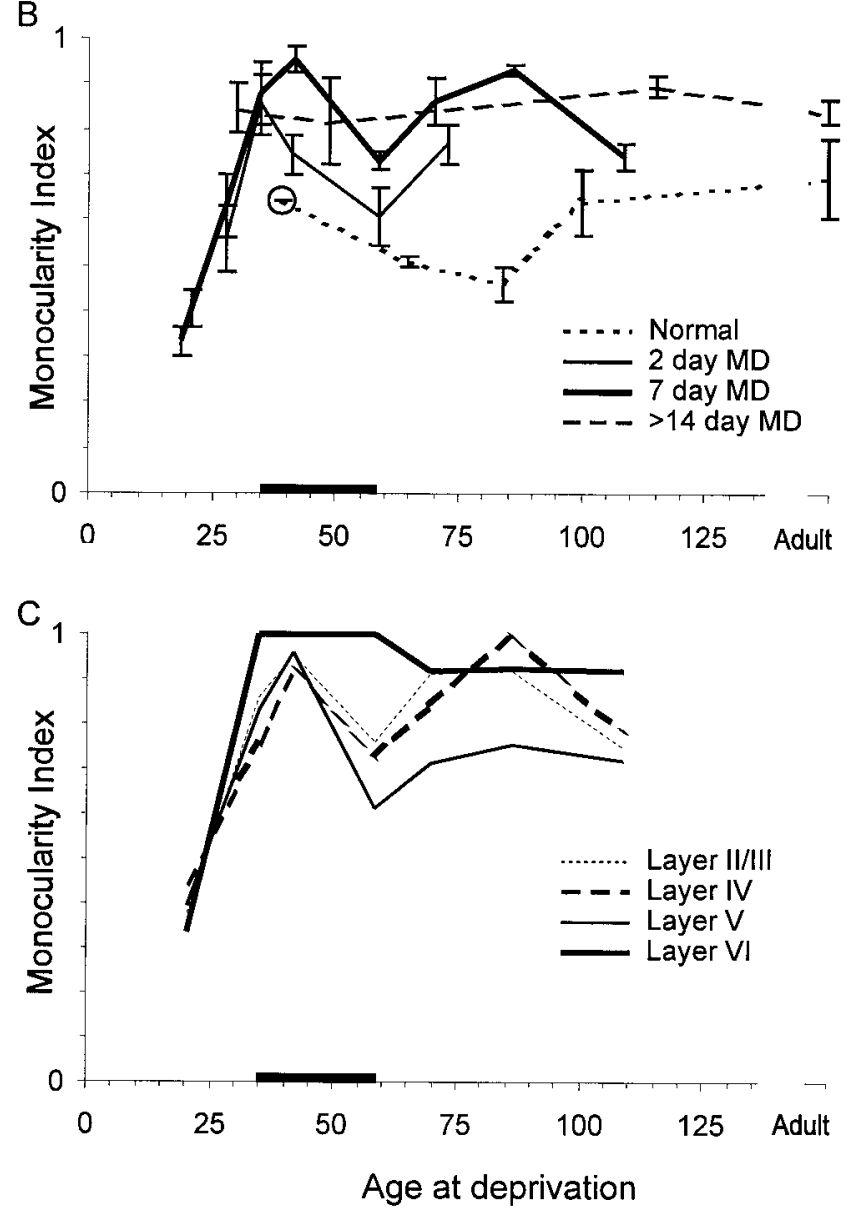

Figure 3. The effect of monocular deprivation on monocularity as a function of age. A, Ocular dominance histograms. Ocular dominance histograms are plotted for all units recorded from ferrets older than P86 that were deprived for $7 \mathrm{~d}$ or longer. The eyes are nearly equally represented in both hemispheres, but the fraction of monocularly dominated cells is greater than normal (compare with Figs. 1, 2A). This pattern is similar to that seen in strabismic animals. $B$, Monocularity index. The monocularity index for each series of monocular deprivations is plotted as a function of age at the beginning of deprivation. The monocularity index is a measure of how exclusively monocular a population of cells is: the larger the monocularity index, the fewer cells respond to both eyes. The $7 \mathrm{~d}$ (heavy solid line) and $2 \mathrm{~d}$ (solid line) MD series show two periods during which MD causes an increase in monocularity compared to normals (dotted line). The first period ( $\sim \mathrm{P} 35-\mathrm{P} 60)$ corresponds to the critical period (indicated by heavy line on abscissa here and in Fig. 2) during which changes in $\mathrm{CBI}$ are accompanied by an increase in MI. The second period, starting around P70 and extending into adulthood, is characterized by an increase in MI without a change in CBI. Dashed line, $>14 \mathrm{~d}$ deprivations. Error bars indicate SEM; the circled point has only one hemisphere contributing to the monocularity index. $C$, Laminar analysis. The monocularity index for the series of $7 \mathrm{~d}$ MDs is plotted as a function maps from an animal that did not have an ocular dominance shift $(F-J$, F322E; SI $=-0.26 ; 2$ d MD at P72; Table 2$)$. The weak response to the deprived eye in the former case is reflected in the noisy angle map of that eye (Fig. $5 E$ ); whereas the angle map made through the nondeprived eye is uniformly strong (Fig. $5 A$ ). To assess quantitatively the difference in cortical activity reflected in maps of the intrinsic signal, we calculated the optical CBI for each hemisphere imaged. For the hemisphere shown in Figure $5 A-E$, for example, the optical CBI of 0.96 is consistent with the large electrophysiologically determined CBI of 1.00; whereas the optical CBI of 0.48 measured in the case illustrated in Figure $5 F-J$ reveals responses to the two eyes that are nearly equal, as in normal animals. As an independent measure of the shift in ocular dominance induced by MD, the optical CBIs validated the trends observed in the single unit measurements. For the set of cortical hemispheres in which both an optical and an electrophysiological CBI were measured, the optical CBI scaled linearly with the electrophysiological CBI (slope $=0.80$; y intercept $=0.06 ; R^{2}=$ $0.80)$. A shift index of 0.74 was calculated from the mean of optical CBIs of animals deprived during the most sensitive part of the critical period; this index was only 0.05 for brief deprivations after the critical period (for ages and durations of deprivation, see Table 2).

In the cat, monocular deprivation causes most of the cortex to lose strong responses from the deprived eye, whereas neurons in the patches of cortex that retain strong responses to the deprived eye largely lose selectivity for stimulus orientation (Crair et al., 1997b). Similar deprived-eye patches also appear in the ferret after monocular deprivation. Three such patches are indicated with an $x$ in Figure 5D. In an HLS map, the level of activity is proportional to lightness; the three light regions marked in Figure $5 D$ were therefore more active when stimulated through the deprived eye than was the rest of the imaged cortex. The degree of orientation selectivity at a given pixel is represented by the color saturation at the pixel; the absence of color in Figure $5 D$ is consistent with the loss of orientation-specific responses in the deprived-eye patches. In contrast, cortical responses to nondeprived eye stimulation are generally well oriented (Fig. 5B, large colored area) and are active everywhere, except in the few places where there are strong deprived-eye responses (the light areas in Fig. $5 D$ are dark in Fig. $5 B$ ). In all six sets of images from animals deprived at the peak of the critical period for at least $7 \mathrm{~d}$, deprived eye patches showed no evidence of orientation selectivity. In the older animal (Fig. $5 F-J$ ), in which deprivation had no effect on the electrophysiologically measured shift index, orientation-specific domains are evident in maps from both eyes. For each eye, orientation maps are strongest in areas dominated by that eye (regions in Fig. $5 F, J$ that are lightest in $G, I$, respectively) and are weaker and more noisy in areas dominated by the other eye (corresponding to dark regions in Fig. 5G,I).

\section{$\longleftarrow$}

of age at the beginning of monocular deprivation for each cortical layer. The laminar changes in monocularity index that occur during the critical period are analogous to the changes seen in ocular dominance; layer VI is the most affected and layer IV the least. After P70, MD produces large shifts to monocularity in layers II/III, IV, and VI, but little shift in layer $\mathrm{V}$. The dip in monocularity index at P60 seen in the $2 \mathrm{~d}$ MD series $(C)$ and in layers II-V in the $7 \mathrm{~d}$ MD series suggests that the strabismus-like effect of late MD is independent of the plasticity observed in the critical period. 
Contralateral eye
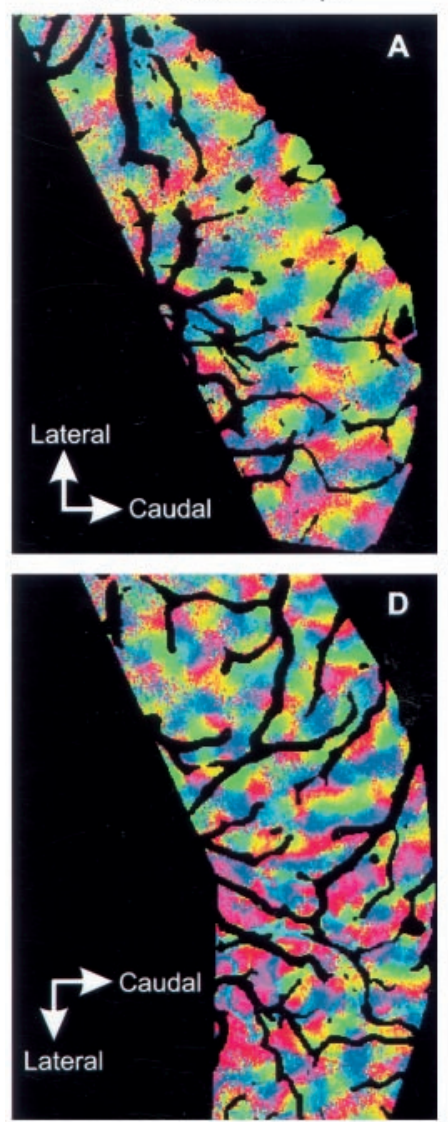

Ocular dominance
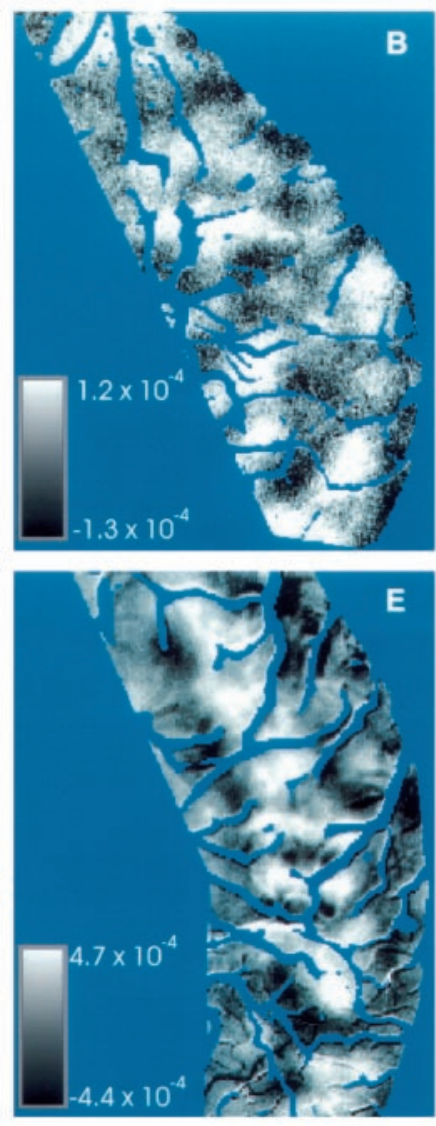

Ipsilateral eye
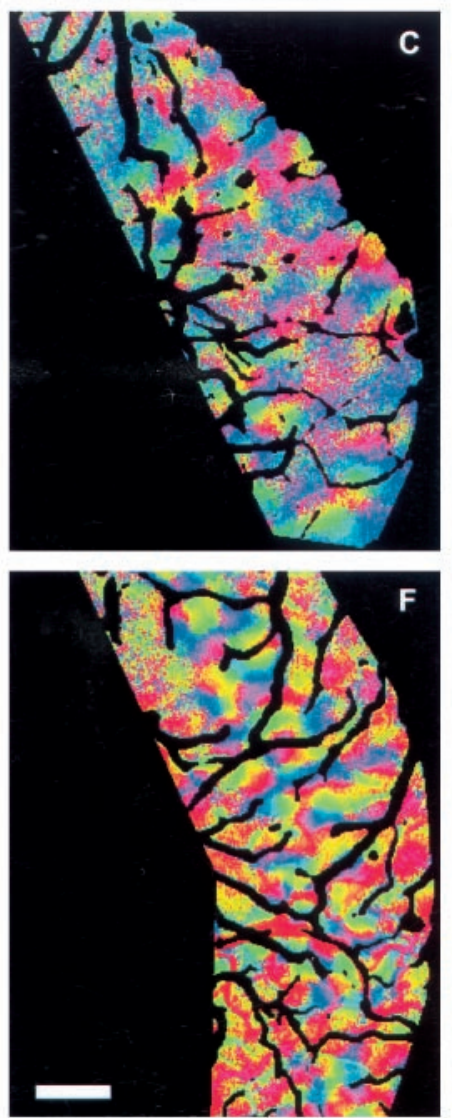

135

90

45
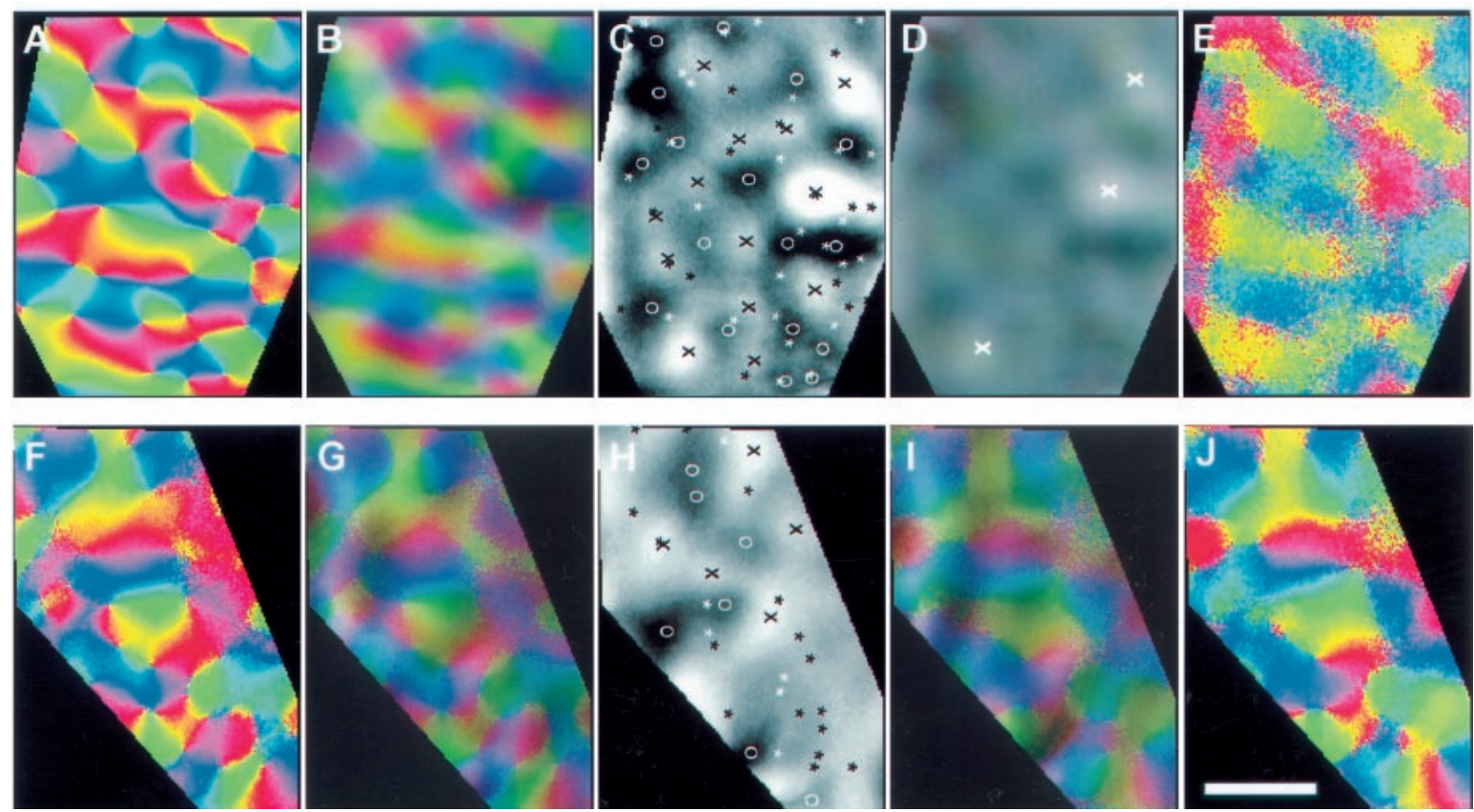

Figure 4. Top. Ocular dominance and orientation maps in normal ferret visual cortex. Angle maps, in which hue represents the best angle to which cortex at a given pixel responds (see color bar), are shown for one adult ferret in $A$ and $C$ and one P71 ferret in $D$ and $F$. $A$ and $D$ are constructed from images taken while stimulating the eye contralateral to the hemisphere, and $C$ and $F$ are from images taken while stimulating the ipsilateral eye. In each figure, the regions dominated by the stimulated eye have well organized orientation pinwheels; the regions dominated by the unstimulated eye have little organization. $B$ and $E$ are ocular dominance ratio maps constructed by dividing the activity in the contralateral maps $(A, D)$ by the ipsilateral maps $(C$, $F)$. Dark regions represent cortex dominated by the contralateral eye, and light regions represent cortex dominated by the ipsilateral eye. The values listed next to the grayscale calibration bar represent the range of intensity modulation around the cocktail blank value of 1.0. Portions of both areas V1 and V2 are shown. Vascular artifacts are overlaid with background color. Scale bar, $1 \mathrm{~mm}$ (in all panels). 
Table 2. Comparison between electrophysiological and optical imaging measures of the effects of monocular deprivation

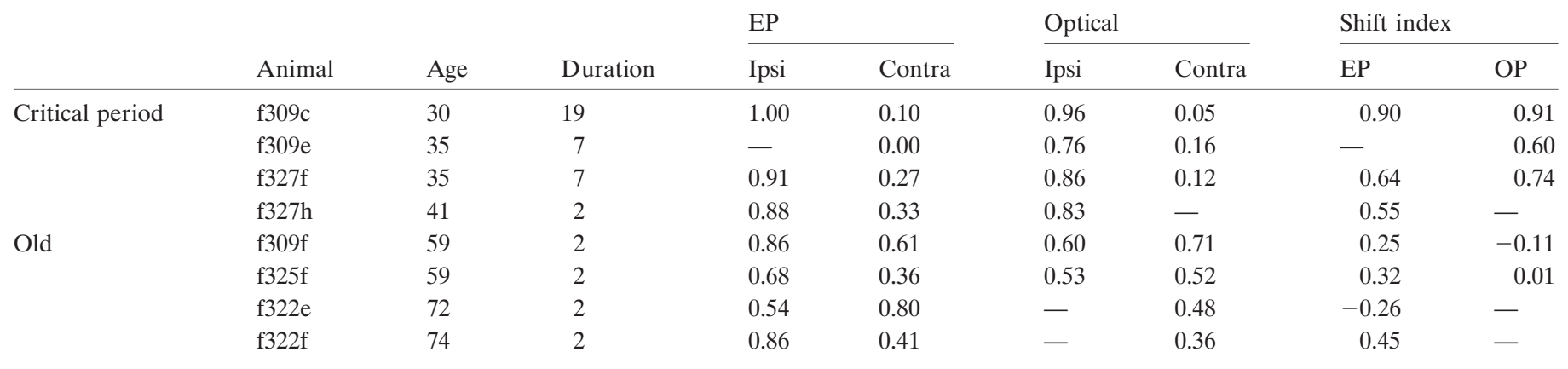

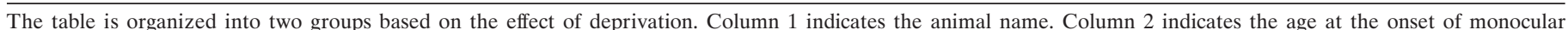

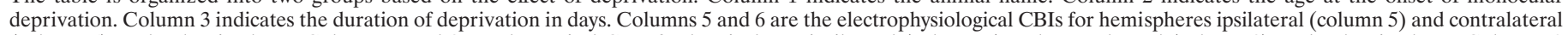

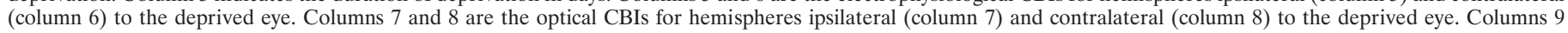
and 10 are the shift indices calculated from the electrophysiological CBIs (column 9) and the optical CBIs (column 10).

Intrinsic signal-imaging experiments on monocularly deprived cats also found that most of the patches of strong cortical responses to the deprived eye were located near pinwheel centers (Crair et al., 1997b). To examine this in ferrets, we determined the positions of pinwheel centers and the peaks of ocular dominance columns in maps from monocularly deprived animals. Visual inspection of the peaks and pinwheels plotted in Figure 5 suggests that there may be a weak correlation between pinwheel centers and ocular dominance column peaks. To address this possibility quantitatively, we performed a Monte Carlo analysis of the distribution of peak to pinwheel distances. For each Monte Carlo simulation, pinwheel centers were placed randomly on an image, keeping the positions of ocular dominance peaks fixed and the numbers of pinwheels in the image constant. The actual distribution of distances of deprived-eye patches from pinwheel centers in the four ferrets analyzed was not statistically different from the Monte Carlo simulation (Fig. 6, group 1). There was also no statistically significant association of pinwheel centers with ocular dominance peaks in three other conditions (Kolmogorov-Smirnov one-sample test; $p>0.05$ for all groups). These included measurements from animals that were deprived at the peak of the critical period and stimulated through the nondeprived eye (group 2), or animals deprived after the peak of the critical period that were stimulated through the deprived (group 3) or nondeprived (group 4) eyes (Fig. 6). It is likely, therefore, that there is no fixed relationship between pinwheel centers and ocular dominance peaks, either in animals strongly affected by deprivation or in animals with little or no effect.

One reason that the relationship between ocular dominance peaks and orientation pinwheels in the ferret may differ from that of the cat is that there are many more pinwheels than ocular dominance peaks in the ferret, whereas the numbers of these two features are similar to one another in the cat (Crair et al., 1997a). In four ferrets that were deprived after the peak of the critical period and had small shift indices, there were $4.37 \pm 0.40$ (mean $\pm \mathrm{SEM} ; n=6$ hemispheres) pinwheel centers $/ \mathrm{mm}^{2}$ but only $2.14 \pm 0.29$ (mean \pm SEM; $n=6$ hemispheres) ocular dominance columns $/ \mathrm{mm}^{2}$. Because of the mismatch in numbers of ocular dominance peaks and pinwheel centers observed on the dorsal surface of the lateral gyrus, it is impossible for each pinwheel center to be associated with an ocular dominance peak. It should be noted, however, that the density of ocular dominance columns observed in this study may differ significantly from the average density of ocular dominance columns in ferret V1 since intrinsic-signal imaging was restricted to the dorsal surface of the ferret's lateral gyrus. Several anatomical studies have shown that the ocular dominance columns on the dorsal surface are larger than those typically found on the ventral and caudal surfaces (Rockland, 1985; Law et al., 1988; Redies et al., 1990; Ruthazer et al., 1999). The number of pinwheels and ocular dominance

\section{$\leftarrow$}

Figure 5. Bottom. The effects of monocular deprivation on optical maps of ferret visual cortex. $A-E$ are from an animal in which monocular deprivation produced a large shift in ocular dominance as measured electrophysiologically (animal F309C, SI $=0.90$, deprived at P30 for $19 \mathrm{~d}$ ). $F-J$ are from an animal in which monocular deprivation produced no electrophysiologically measured shift in ocular dominance (animal F322E, SI $=-0.26$, deprived at P72 for $2 \mathrm{~d}$ ). A, F, Angle maps produced by stimulating the nondeprived eye. As in Figure 4, regions with well organized orientation maps are dominated by the stimulated eye, and regions with little structure are dominated by the nonstimulated eye. Complementary regions of ocular dominance are apparent in $E$ and $J$. In $A$, the nondeprived eye effectively stimulated all of the imaged region; areas in which the deprived eye was somewhat effective in driving cortical responses are seen more clearly in $B-D . B, G$, HLS maps produced by stimulating the nondeprived eye. In HLS maps, hue represents the best angle, lightness represents the magnitude of cortical response, and saturation represents the degree of orientation selectivity. Black regions are therefore areas of cortex dominated by the nonstimulated eye, and white regions are active, but are poorly tuned to an orientation. Colored regions are active and well tuned. $C, H$, Ocular dominance ratio maps were produced by dividing the activity in maps from the nondeprived eye (dark) by activity in maps from the deprived eye (light). Pinwheel centers, identified on the angle maps, are plotted as $\star$. Peaks of nondeprived-eye columns are plotted as $\bigcirc$, and peaks of deprived-eye columns are plotted as $x$. Local extrema in the ocular dominance map were selected as peaks of ocular dominance columns. There is no consistent relationship between the positions of ocular dominance peaks and pinwheel centers in either the strongly shifted $(C)$ or the unshifted $(H)$ cortex. In $C$, intensity ranges from $-1.5 \times 10^{-4}$ (black) to $+1.4 \times 10^{-4}$ (white) around the mean cocktail-blank intensity of 1.0 . In $H$, intensity ranges from $-2.4 \times 10^{-4}$ to $1.7 \times 10^{-4}$. $D$, I, HLS maps produced by stimulating the deprived eye. The areas in $D$ that appear to be active lack orientation tuning (white areas, three of which are marked with $x$ ), consistent with the fact that prolonged monocular deprivation degrades orientation-specific cortical responses to deprived-eye stimuli. There are several active areas in $I$ that are also selective for orientation (light-colored but with clear hues), consistent with the weak effect of $2 \mathrm{~d}$ deprivation at P72. Note also that $D$ is very different from $B$, indicating a strong deprivation effect, whereas $I$ is similar to $G$, consistent with the lack of an effect of deprivation. $E, J$, Angle maps produced by stimulating the deprived eye. 


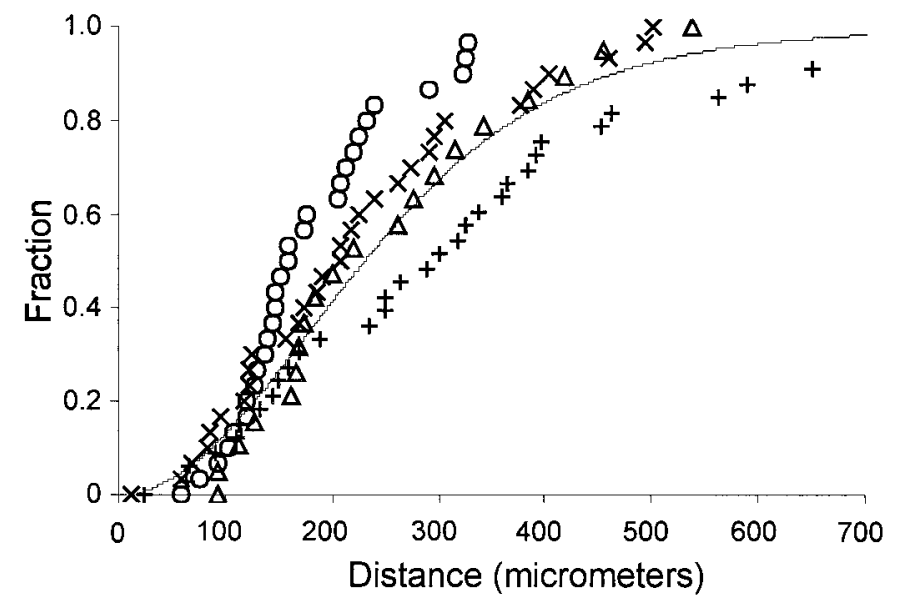

Figure 6. Monte Carlo analysis of pinwheel-peak distances. To determine whether pinwheel centers in the ferret are closer to peaks of ocular dominance columns than would be expected by chance, we performed a Monte Carlo analysis of distances between pinwheel centers and ocular dominance peaks. The positions of pinwheel centers and ocular dominance peaks were determined for each hemisphere imaged. The distance between each ocular dominance peak and its nearest pinwheel center was measured. The distributions of pinwheel-peak distances were grouped by developmental stage and eye stimulated. Group 1, Critical period animals stimulated through the deprived eye $(x)$; group 2, critical period, nondeprived eye $(\bigcirc)$; group 3 , old, deprived eye $(+)$; group 4, old, nondeprived $(\triangle)$. For each group, the cumulative distribution is plotted against distance. For the Monte Carlo analysis, each imaged hemisphere was treated individually: the same number of pinwheels as was in the original image was placed randomly on the image, whereas ocular dominance peaks were not moved. The distributions of distances produced from 5000 simulations on each map were grouped into a single cumulative distribution (solid line). There was no statistical difference between any of the four distributions and their image-appropriate Monte Carlo distribution (Kolmogorov-Smirnov one-sample test; $p>0.05$ ).

peaks may be better matched on the ventral and caudal surfaces of the ferret's lateral gyrus.

\section{DISCUSSION}

\section{The critical period for ocular dominance plasticity in the ferret}

We have characterized the time course of the effect of monocular lid suture on ocular dominance plasticity in the ferret. Cortical susceptibility to monocular deprivation begins around P35, a few days after natural eye opening, and peaks around P42.The critical period in the ferret therefore has a clear beginning that is later than the time at which neurons in the visual cortex begin to respond well to visual stimulation. In the present experiments, no ocular dominance shifts were found in 411 units recorded in eight animals in which monocular deprivation ended before postnatal day 30 (2 d MD at P28 and 7 d MD at P19 and P21; Table 1). By $\mathrm{P} 30$, responses of visual cortical neurons are strong, despite the fact that most neurons lack orientation selectivity (Chapman and Stryker, 1993). The finding of a beginning to the critical period is consistent with similar results found in the mouse (Gordon and Stryker, 1996) and in several studies of the cat (Hubel and Wiesel, 1970; Olson and Freeman, 1980).

As has been found in other species (LeVay et al., 1978, 1980), the ferret's critical period for ocular dominance plasticity coincides with the period during which geniculocortical projections to V1 are refined. The beginning of the critical period corresponds closely to the age at which ocular dominance columns can first be detected by transneuronal labeling techniques (Finney and Shatz,
1998; Ruthazer et al., 1999). Similarly, the end of the most sensitive part of the critical period, P60, corresponds with the age at which transneuronal labeling reveals ocular dominance columns of mature appearance (Ruthazer et al., 1999). Together with the transneuronal studies, the physiologically identified critical period defines the time course of ocular dominance column development in the ferret.

The duration of deprivation had a profound effect on the extent of cortical changes. While $7 \mathrm{~d}$ deprivations were sufficient to induce a saturating shift in ocular dominance, $2 \mathrm{~d}$ deprivations were $\sim 70 \%$ as effective. The ferret cortex therefore changes more slowly in response to monocular deprivation than does the cat cortex, in which $2 \mathrm{~d}$ of deprivation produces a saturating ocular dominance shift (Crair et al., 1997b). Although the factors underlying this interspecies difference are obscure, structural differences between cat and ferret V1 may account for it. In the ferret, cortical cells are more monocular at the onset of the critical period than are cells in cat V1. The normal critical period age ferrets studied here had an average monocularity index slightly larger than that of critical period kittens $(0.56 \pm 0.04$ critical period ferrets, $n=3$ hemispheres vs $\sim 0.45$ in 3- to 4-week-old cats, estimated from Hubel and Wiesel, 1970, Crair et al., 1998). Because the population of cells in ferret V1 is more monocular than that in cat V1, competition between eyes may proceed more slowly (Mustari and Cynader, 1981).

The larger average size of ferret ocular dominance columns means there is less border length between opposite-eye columns in a given area of ferret cortex than in cat cortex. If changes in ocular dominance proceed along ocular dominance column borders, the smaller border length in the ferret may slow the overall progress of ocular dominance changes. NMDA receptors, which have been implicated in cortical plasticity associated with MD in vivo (Kleinschmidt et al., 1987; Bear et al., 1990; Roberts et al., 1998), have been demonstrated to be organized into patches that coalign with borders of ocular dominance columns in the cat (Trepel et al., 1998, but see Catalano et al., 1997). The relative paucity in ocular dominance borders, and therefore smaller NMDA-receptor-rich areas, if they exist in the ferret, may account for the slower progress of plasticity in the ferret.

\section{Strabismus-like changes in the adult}

Monocular deprivation that starts after the critical period causes an effect like that of strabismus in the ferret visual cortex. After late-onset deprivation, each eye is represented to a normal extent in V1, but few cells are driven by both eyes. In earlier studies in other species, such a shift to monocularity was associated with strabismus during the critical period (Hubel and Wiesel, 1965). Under these conditions, equal cortical activity from the two eyes maintains the appropriate balance of eye inputs, but because the activity is uncorrelated, binocular interactions are minimized. With monocular deprivation, activity in the two eyes is uncorrelated, but also imbalanced. During the critical period the imbalance in activity causes a loss of deprived-eye inputs, but with deprivations begun after the critical period, the lack of correlation between inputs seems to be the more significant patterning force.

A loss of binocularity has also been observed in cats that were monocularly deprived either very briefly or at the end of the critical period (Hubel and Wiesel, 1970; Olson and Freeman, 1980). The loss of binocularity in such mildly deprived cats can be explained as a loss of responsiveness to the deprived eye by the formerly binocular cells, for which both eyes could compete 


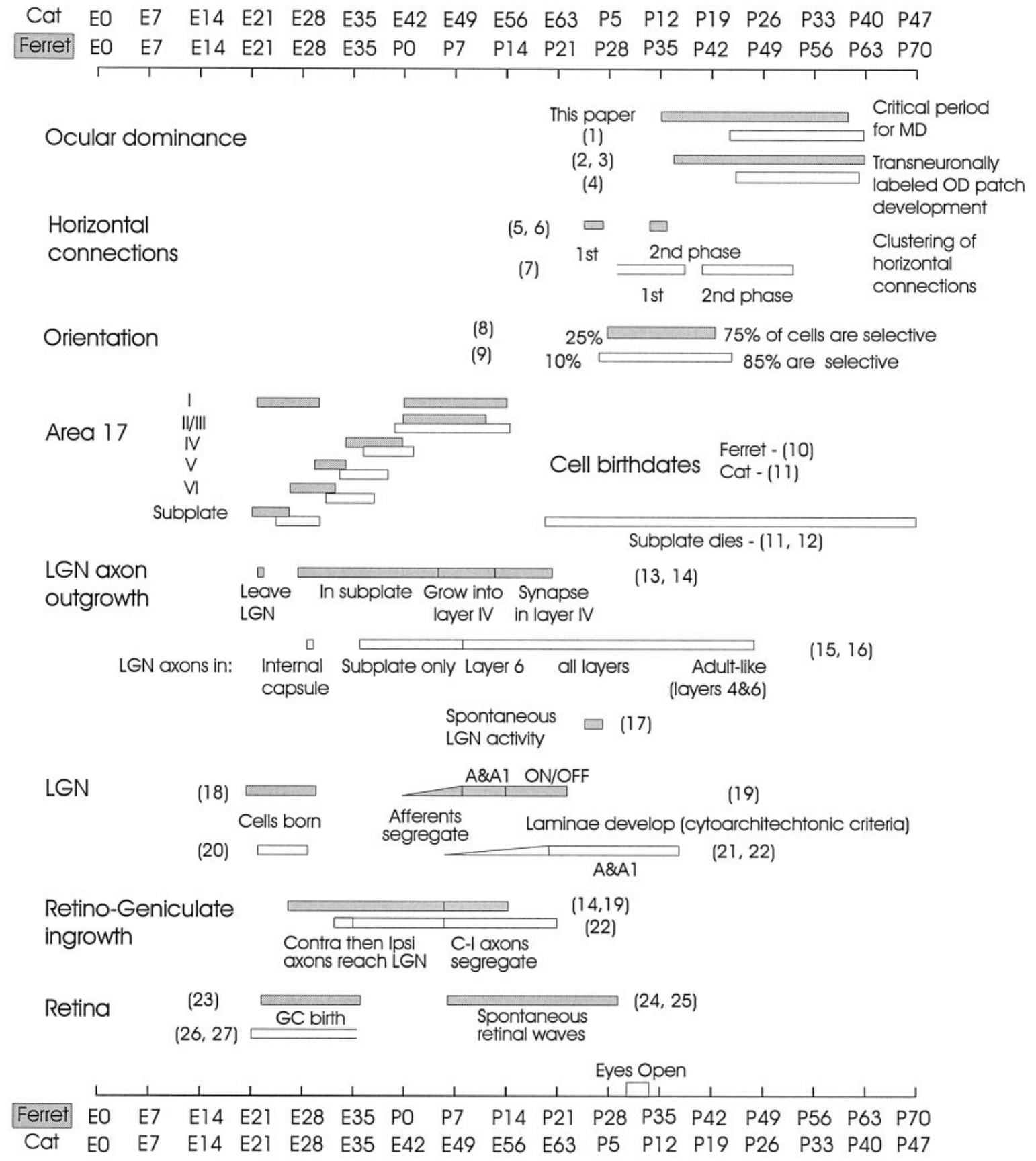

Figure 7. Timeline of developmental milestones in the visual system; comparison of the ferret to the cat. Developmental milestones in the visual cortex, LGN, and retina are displayed for both species. The development of the ferret's visual system has been thought to proceed with the same postconception time course as that of the cat. Several events, however, occur earlier in the ferret than in the cat. In addition to an earlier beginning to the critical period and ocular dominance segregation, cortical horizontal connections begin to cluster earlier, most cortical cells are born earlier, and LGN lamination, axonal growth, and cortical invasion occur earlier in the ferret than in the cat. Other subcortical developmental time points are more closely matched between the two species. $O D$, Ocular dominance; $M D$, monocular deprivation; $G C$, ganglion cell; $C$-I, contralateral-ipsilateral. References: 1 , Hubel and Wiesel (1970); 2, Finney and Shatz (1998); 3, Ruthazer et al. (1999); 4, LeVay et al. (1978); 5, Durack and Katz (1996); 6, Ruthazer and Stryker (1996); 7. Callaway and Katz (1990); 8, Chapman and Stryker (1993); 9, Albus and Wolf (1984); 10, Jackson et al. (1989); 11, Luskin and Shatz (1985); 12, Valverde and Facal-Valverde (1988); 13, Hermann et al. (1994); 14, Johnson and Casagrande (1993); 15, Shatz and Luskin (1986); 16, Ghosh and Shatz (1992); 17, Weliky and Katz (1998); 18, Peduzzi (1989); 19, Linden et al. (1981); 20, Hickey and Hitchcock (1984); 21, Kalil (1978); 22, Shatz (1983); 23, Reese et al. (1994); 24, Meister et al. (1991); 25, Wong et al. (1993); 26, Walsh et al. (1983); 27, Walsh and Polley (1985).

(Shatz and Stryker, 1978; Olson and Freeman, 1980). Cells initially driven exclusively by the deprived eye remain responsive to that eye because of the reduced opportunity for competition. In this case, few cells remain binocular (equivalent to a large monocularity index), but the majority of the cortex is dominated by the nondeprived eye (equivalent to a large shift index). In the ferret, however, there is not a loss of cells dominated by the deprived eye; the shift index in deprived adult ferrets, as in normal ferrets, is near zero. Thus, a major difference between the loss of binocularity observed in mildly deprived cats and that 
observed in deprived adult ferrets is the lack of a concomitant shift in overall ocular dominance (CBI) in the ferret.

A pattern of age-dependent deprivation effects similar to that observed in the ferret was seen by Kasamatsu et al. (1979) in cats that received norepinephrine inf usions into visual cortex. These workers suggested that a first stage of the response to monocular deprivation was a loss of binocular responsiveness rather than a loss of responses to the deprived eye and that this process was enhanced by norepinephrine in older animals. If the strabismuslike changes in the adult ferret are analogous to those in the norepinephrine-treated cat, then one may speculate that the level of tonic input to visual cortex from the central noradrenergic system is comparatively high in the adult ferret.

The finding that monocular deprivation can produce a strabismus-like pattern of cortical activity may be relevant to a type of secondary strabismus found in humans after prolonged monocular deprivation by cataract. Studies in nonhuman primates suggest that visual deprivation can cause strabismus. Various protocols of monocular deprivation begun near the time of birth of a monkey can produce interocular misalignment (Quick et al., 1989), whereas binocular deprivation at young ages can cause a loss of binocularly responsive cortical neurons (Wiesel and Hubel, 1974). Similar to findings in visually deprived monkeys, children with corrected congenital cataract can develop a secondary strabismus with attendant amblyopia and poor stereopsis (for review, see Maurer and Lewis, 1993). In a small fraction of adults, furthermore, a secondary strabismus with central fusion disruption can develop when a monocular cataract is present for $>2$ years (Pratt-Johnson and Tillson, 1989). Because visual acuity is not significantly degraded after the removal of such a cataract, the development of secondary strabismus likely reflects a loss of cortical binocularity similar to that seen in the monocularly deprived adult ferret. Although strabismus has been seen with monocular deprivation in young animals (Sherman, 1972; Quick et al., 1989), it has not been possible to separate the physiological effects of MD-induced strabismus from the consequences of the degradation of cortical responses to the deprived eye. Because strabismus-like changes in the adult ferret develop in the absence of an overall shift in ocular dominance, study of the monocularly deprived adult ferret may give insight into the pathology and prevention of secondary strabismus. It should be noted, however, that available findings do not establish whether the changes in cortical binocularity produced by MD in the adult ferret are reversible or whether they would give rise to strabismus.

\section{Intrinsic signal imaging}

We assessed the effects of monocular deprivation on orientation and ocular dominance maps by imaging intrinsic cortical signals. Maps of V1 and V2 from monocularly deprived ferrets were consistent with the findings of monocular deprivation studies in cat (Crair et al., 1997b) in demonstrating well-oriented responses to nondeprived-eye stimulation and weak or absent responses to deprived-eye stimulation, except in patches, within which strong responses were poorly selective for orientation. The results from the ferret differed from those of the cat in that no clear relationship between pinwheel centers and ocular dominance peaks was found. The cat may represent a special case in this regard. Crair et al. (1997b) proposed that pinwheel centers and ocular dominance peaks colocalize because they develop under a shared learning rule. The similarity of the number of pinwheels $(\sim 2.2$ pinwheels $/ \mathrm{mm}^{2}$; Bonhoeffer et al., 1995, Rao et al., 1997) to the number of ocular dominance peaks $\left(\sim 2.7\right.$ peaks $/ \mathrm{mm}^{2}$; Crair et al., 1997a) in cat V1 may allow their alignment through a weak correlation-based rule that is ineffective when orientation pinwheels vastly outnumber ocular dominance peaks, as is the case in the ferret (see Results).

Given the lack of coincidence of ocular dominance peaks and pinwheel centers in the normal ferret, it is not surprising that there is no clear relationship after monocular deprivation. In both cats and ferrets, deprived-eye patches lose their orientation selectivity. In the deprived cats, however, the deprived-eye patches are even closer to the pinwheel centers than in normal animals. Crair et al. (1997b) proposed that this was attributable to an advantage that cells at pinwheel centers, which may be poorly oriented (in kittens, Ruthazer et al., 1996; but see Maldonado et al., 1997 on adult cats), have over neighboring orientationselective regions when competition is based on response to nonoriented activity, as would be the case for cells driven through the deprived eye. In the ferret, the same simple learning rule can explain the loss of orientation selectivity in deprived-eye patches: deprived-eye inputs, stimulated only by unpatterned retinal activity, maintain or strengthen only unoriented connections.

\section{Comparison with the development of the cat}

Figure 7 summarizes several milestones in the development of the ferret and cat visual systems (with references given in the figure) in relation to the critical period defined in this report. The rates of development of the cat's and the ferret's visual systems are generally similar starting from the day of conception rather than the time of birth (Linden et al., 1981). The cat's gestational period is $21 \mathrm{~d}$ longer than the ferret's, and its eyes open $\sim 21$ postnatal days before the eyes of the ferret. Taking into account additional parameters of visual development, it becomes apparent that several features of the ferret's visual system develop earlier than in the cat. The ferret's LGN becomes laminated and extends axons into visual cortex $\sim 1$ week before the cat's LGN does. Most cells in the ferret visual cortex, with the exception of layer II/III cells, are born 2-5 d earlier than their cat counterparts. In addition, ocular dominance column formation occurs somewhat earlier in the ferret. The cat's critical period begins 82-87 d after conception ( $\sim$ P21; Hubel and Wiesel, 1970), whereas the ferret's begins $\sim 75 \mathrm{~d}$ after conception $(\sim \mathrm{P} 35)$. This is consistent with transneuronal studies in which ferret ocular dominance columns first appear around P37, postconception day 79, and cat ocular dominance columns appear by $\mathrm{P} 22$, cat postconception day 87 . Overall, although the same events in the two species occur in nearly the same order, the pace of development appears to be slightly more rapid in the ferret.

\section{REFERENCES}

Albus K, Wolf W (1984) Early post-natal development of neuronal function in the kitten's visual cortex: a laminar analysis. J Physiol (Lond) 348:153-185.

Antonini A, Stryker MP (1993a) Development of individual geniculocortical arbors in cat striate cortex and effects of binocular impulse blockade. J Neurosci 13:3549-3573.

Antonini A, Stryker MP (1993b) Rapid remodeling of axonal arbors in the visual cortex. Science 260:1819-1821.

Bear MF, Kleinschmidt A, Gu Q, Singer W (1990) Disruption of experience-dependent synaptic modifications in striate cortex by infusion of an NMDA receptor antagonist. J Neurosci 10:909-925.

Bonhoeffer T, Grinvald A (1996) Optical imaging based on intrinsic signals; the methodology. In: Brain mapping: the methodology, pp7597. New York: Academic.

Bonhoeffer T, Kim D-S, Malonek D, Shohem D, Grinvald A (1995) Optical imaging of the layout of functional domains in area 17 and 
across the area $17 / 18$ border in cat visual cortex. Eur J Neurosci 7:1973-1988.

Callaway EM, Katz LC (1990) Emergence and refinement of clustered horizontal connections in cat striate cortex. J Neurosci 10:1134-1153.

Callaway EM, Lieber JL (1996) Development of axonal arbors of layer 6 pyramidal neurons in ferret primary visual cortex. J Comp Neurol 376:295-305.

Catalano SM, Chang CK, Shatz CJ (1997) Activity dependent regulation of NMDAR1 immunoreactivity in the developing visual cortex. J Neurosci 17:8376-8390.

Chapman B, Stryker MP (1993) Development of orientation selectivity in ferret visual cortex and effects of deprivation. J Neurosci 13:5251-5262.

Chapman B, Zahs KR, Stryker MP (1991) Relation of cortical cell orientation selectivity to alignment of receptive fields of the geniculocortical afferents that arborize within a single orientation column in ferret visual cortex. J Neurosci 11:1347-1358.

Chapman B, Stryker MP, Bonhoeffer T (1996a) Development of orientation preference maps in ferret primary visual cortex. J Neurosci 16:6443-6453.

Chapman B, Zahs KR, Harris SL, Stryker MP (1996b) Plasticity following monocular deprivation in ferret primary visual cortex. Soc Neurosci Abstr 22:1727.

Crair MC, Ruthazer ES, Gillespie DC, Stryker MP (1997a) Ocular dominance peaks at pinwheel center singularities of the orientation map in cat visual cortex. J Neurophysiol 77:3381-3385.

Crair MC, Ruthazer ES, Gillespie DC, Stryker MP (1997b) Relationship between the ocular dominance and orientation maps in visual cortex of monocularly deprived cats. Neuron 19:307-318.

Crair MC, Gillespie DC, Stryker MP (1998) The role of visual experience in the development of columns in cat visual cortex. Science 279:566-570.

Dalva MB, Katz LC (1994) Rearrangements of synaptic connections in visual cortex revealed by laser photostimulation. Science 265:255-258.

Dantzker JL, Callaway EM (1998) The development of local, layerspecific visual cortical axons in the absence of extrinsic influences and intrinsic activity. J Neurosci 18:4145-4154.

Daw NW, Fox K, Sato H, Czepita D (1992) Critical period for monocular deprivation in the cat visual cortex. J Neurophysiol 67:197-202.

Durack JC, Katz LC (1996) Development of horizontal projections in layer 2/3 of ferret visual cortex. Cereb Cortex 6:178-183.

Finney EM, Shatz CJ (1998) Establishment of patterned thalamocortical connections does not require nitric oxide synthase. J Neurosci 18:8826-8838.

Ghosh A, Shatz CJ (1992) Pathfinding and target selection by developing geniculocortical axons. J Neurosci 12:39-55.

Gordon JA, Stryker MP (1996) Experience-dependent plasticity of binocular responses in the primary visual cortex of the mouse. J Neurosci $16: 3274-3286$.

Hermann K, Antonini A, Shatz CJ (1994) Ultrastructural evidence for synaptic interactions between thalamocortical axons and subplate neurons. Eur J Neurosci 6:1729-1742.

Hickey TL, Hitchcock PF (1984) Genesis of neurons in the dorsal lateral geniculate nucleus of the cat. J Comp Neurol 228:186-199.

Hirsch JA (1995) Synaptic integration in layer IV of the ferret striate cortex. J Physiol (Lond) 483:183-199.

Hubel DH, Wiesel TN (1962) Receptive fields, binocular interaction and functional architecture in the cat's visual cortex. J Physiol (Lond) 160:106-154.

Hubel DH, Wiesel TN (1965) Binocular interaction in striate cortex of kittens reared with artificial squint. J Neurophysiol 28:1041-1051.

Hubel DH, Wiesel TN (1970) The period of susceptibility to the physiological effects of unilateral eye closure in kittens. J Physiol (Lond) 206:419-436.

Hubel DH, Wiesel TN, LeVay S (1977) Plasticity of ocular dominance columns in monkey striate cortex. Philos Trans R Soc B Biol Sci 278:131-163.

Hubener M, Shoham D, Grinvald A, Bonhoeffer T (1997) Spatial relationships among three columnar systems in cat area 17. J Neurosci 17:9270-9284.

Jackson CA, Hickey TL (1985) Use of ferrets in studies of the visual system. Lab Anim Sci 35:211-215.

Jackson CA, Peduzzi JD, Hickey TL (1989) Visual cortex development in the ferret. I. Genesis and migration of visual cortical neurons. J Neurosci 9:1242-1253.
Johnson JK, Casagrande VA (1993) Prenatal development of axon outgrowth and connectivity in the ferret visual system. Vis Neurosci 10:117-130.

Kalil R (1978) Development of the dorsal lateral geniculate nucleus in the cat. J Comp Neurol 182:265-292.

Kasamatsu T, Pettigrew JD, Ary M (1979) Restoration of visual cortical plasticity by local microperfusion of norepinephrine. J Comp Neurol 185:163-181.

Kleinschmidt A, Bear MF, Singer W (1987) Blockade of "NMDA" receptors disrupts experience-dependent plasticity of kitten striate cortex. Science 238:355-358.

Law MI, Zahs KR, Stryker MP (1988) Organization of primary visual cortex (area17) in the ferret. J Comp Neurol 278:157-180.

LeVay S, Stryker MP, Shatz CJ (1978) Ocular dominance columns and their development in layer IV of the cat's visual cortex: a quantitative study. J Comp Neurol 179:223-244.

LeVay S, Wiesel TN, Hubel DH (1980) The development of ocular dominance columns in normal and visually deprived monkeys. J Comp Neurol 191:1-51.

Linden DC, Guillery RW, Cucchiaro J (1981) The dorsal lateral geniculate nucleus of the normal ferret and its postnatal development. J Comp Neurol 203:189-211.

Luskin MB, Shatz CJ (1985) Neurogenesis of the cat's primary visual cortex. J Comp Neurol 242:611-631.

Maldonado PE, Gödecke I, Gray CM, Bonhoeffer T (1997) Orientation selectivity in pinwheel centers in cat striate cortex. Science 276:1551-1555.

Maurer D, Lewis TL (1993) Visual outcomes after infantile cataract. In: Early visual development, normal and abnormal (Simons KW, ed), pp 454-484. New York: Oxford UP.

McAllister AK, Lo DC, Katz LC (1995) Neurotrophins regulate dendritic growth in developing visual cortex. Neuron 15:791-803.

McAllister AK, Katz LC, Lo DC (1996) Neurotrophin regulation of cortical dendritic growth requires activity. Neuron 17:1057-1064.

McAllister AK, Katz LC, Lo DC (1997) Opposing roles for endogenous BDNF and NT-3 in regulating cortical dendritic growth. Neuron 18:767-778.

Meister M, Wong ROL, Baylor DA, Shatz CJ (1991) Synchronous bursts of action potentials in ganglion cells of the developing mammalian retina. Science 252:939-943.

Mustari M, Cynader M (1981) Prior strabismus protects kitten cortical neurons from the effects of monocular deprivation. Brain Res 211:165-70.

Nelson DA, Katz LC (1995) Emergence of functional circuits in ferret visual cortex visualized by optical imaging. Neuron 15:23-34.

Olson CR, Freeman RD (1975) Progressive changes in kitten striate cortex during monocular vision. J Neurophysiol 38:26-32.

Olson CR, Freeman RD (1980) Profile of the sensitive period for monocular deprivation in kittens. Exp Brain Res 39:17-21.

Peduzzi JD (1989) Neurogenesis of the geniculate nucleus in the ferret. Soc Neurosci Abstr 15:1210.

Pratt-Johnson J, Tillson G (1989) Intractable diplopia after vision restoration in unilateral cataract. Am J Ophthalmol 107:23-26.

Quick MW, Tigges M, Gammon JA, Boothe RG (1989) Early abnormal visual experience induces strabismus in infant monkeys. Invest Ophthalmol Vis Sci 30:1012-1017.

Rao SC, Toth LJ, Sur M (1997) Optically imaged maps of orientation preference in primary visual cortex of cats and ferrets. J Comp Neurol 387:358-370.

Redies C, Diksic M, Riml H (1990) Functional organization in the ferret visual cortex: a double-label 2-deoxyglucose study. J Neurosci 10:2791-2803.

Reese BE, Thompson WF, Peduzzi JD (1994) Birthdates of neurons in the retinal ganglion cell layer of the ferret. J Comp Neurol 341:464-475.

Reiter HO, Waitzman DM, Stryker MP (1986) Cortical activity blockade prevents ocular dominance plasticity in the kitten visual cortex. Exp Brain Res 65:182-188.

Roberts EB, Meredith MA, Ramoa AS (1998) Suppression of NMDA receptor function using antisense DNA blocks ocular dominance plasticity while preserving visual responses. J Neurophysiol 80:1021-1032.

Rockland KS (1985) Anatomical organization of primary visual cortex (area 17) in the ferret. J Comp Neurol 241:225-236. 
Ruthazer ES, Stryker MP (1996) The role of activity in the development of long-range horizontal connections in area 17 of the ferret. J Neurosci 16:7253-7269.

Ruthazer ES, Crair MC, Gillespie DC, Stryker MP (1996) Orientation tuning of single cells at "pinwheel" orientation singularities in kitten visual cortex. Soc Neurosci Abstr 22:277.

Ruthazer ES, Baker GE, Stryker MP (1999) Development and organization of ocular dominance bands in primary visual cortex of the sable ferret. J Comp Neurol 407:151-165.

Shatz CJ (1983) The prenatal development of the cat's retinogeniculate pathway. J Neurosci 3:482-499.

Shatz CJ, Luskin MB (1986) The relationship between the geniculocortical afferents and their cortical target cells during development of the cat's primary visual cortex. J Neurosci 6:3655-3668.

Shatz CJ, Stryker MP (1978) Ocular dominance in layer IV of the cat's visual cortex and the effects of monocular deprivation. J Physiol (Lond) 281:267-283.

Sherman SM (1972) Development of interocular alignment in cats. Brain Res 37:187-203.

Stryker MP, Harris WA (1986) Binocular impulse blockade prevents the formation of ocular dominance columns in cat visual cortex. J Neurosci 6:2117-2133.

Trachtenberg JT, Issa NP, Stryker MP (1998) Critical period in ferret visual cortex defined by brief monocular deprivation. Soc Neurosci Abstr 24:646.

Trepel C, Duffy KR, Pegado VD, Murphy KM (1998) Patchy distribution of NMDAR1 subunit immunoreactivity in developing visual cortex. J Neurosci 18:3404-3415.

Valverde F, Facal-Valverde MV (1988) Postnatal development of interstitial (subplate) cells in the white matter of the temporal cortex of kittens: a correlated Golgi and electron microscopic study. J Comp Neurol 269:168-192.

Walsh C, Polley EH (1985) The topography of ganglion cell production in the cat's retina. J Neurosci 5:741-750.

Walsh C, Polley EH, Hickey TL, Guillery RW (1983) Generation of cat retinal ganglion cells in relation to central pathways. Nature 302:611-614.

Weliky M, Katz LC (1994) Functional mapping of horizontal connections in developing ferret visual cortex: experiments and modeling. J Neurosci 14:7291-7305.

Weliky M, Katz LC (1997) Disruption of orientation tuning in visual cortex by artificially correlated neuronal activity. Nature 386:680-685.

Weliky M, Katz LC (1998) Spontaneous activity in the developing LGN in vivo: differential regulation of correlational structure by retinal and cortical inputs. Soc Neurosci Abstr 24:1517.

Weliky M, Bosking WH, Fitzpatrick D (1996) A systematic map of direction preference in primary visual cortex. Nature 379:725-728.

White LE, Bosking WH, Fitzpatrick D (1998) Functional architecture of ferret visual cortex: thalamic inputs to identified ocular dominance territories. Soc Neurosci Abstr 24:1755.

Wiesel TN, Hubel DH (1963) Single-cell responses in striate cortex of kittens deprived of vision in one eye. J Neurophysiol 26:1003-1017.

Wiesel TN, Hubel DH (1974) Ordered arrangement of orientation columns in monkeys lacking visual experience. J Comp Neurol 158:307-318.

Wong ROL, Meister M, Shatz CJ (1993) Transient period of correlated bursting activity during development of the mammalian retina. Neuron 11:923-938.

Zahs KR, Stryker MP (1988) Segregation of ON and OFF afferents to ferret visual cortex. J Neurophysiol 59:1410-1429. 